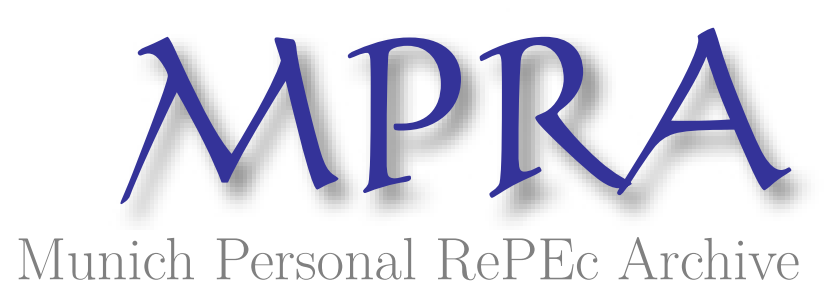

\title{
Bailing on the car that wasn't bailed out: bounding consumer reactions to financial distress
}

Huse, Cristian and Koptyug, Nikita

Stockholm School of Economics, Research Institute for Industrial Economics

1 July 2016

Online at https://mpra.ub.uni-muenchen.de/72796/

MPRA Paper No. 72796, posted 01 Aug 2016 05:47 UTC 


\title{
Bailing On The Car That Wasn’t Bailed Out:
}

\section{Bounding Consumer Reactions to Financial Distress*}

\author{
Cristian Huse $^{\dagger} \quad$ Nikita Koptyug ${ }^{\ddagger}$
}

July 2016

\begin{abstract}
This paper examines how consumers react to the financial distress of durable goods manufacturers by looking at the Swedish new car market. We employ a difference-in-differences matching methodology whereby we compare sales of carmaker Saab with those of a carefully constructed control group of substitute products. To account for possible substitution between products in the treatment and control groups, we propose and apply bounds to our difference-in-differences matching estimator. We then refine the bounds and provide conditions under which they depend only on the products' own- and cross-price elasticities. We find that even accounting for potential substitution, there was a significant decrease in the sales of Saab following its filing for administration. These findings are robust to a number of robustness checks and alternative hypothesis.
\end{abstract}

${ }^{*}$ Nikita Koptyug gratefully acknowledges financial support from the the Foundation of Banking Research and the Jan Wallander and Tom Hedelius foundation. We thank Tobias Olsson at Vroom Stockholm for making data available and participants at the EARIE, Jornadas de Economia Industrial, IIOC, MOITA Workshop, SBE and SSE (Empirical Micro Workshop, Economics and Finance Lunch Seminars) for comments. We are also indebted to Laurent Bach, Áureo De Paula, Bob Hammond, Erik Lindqvist, Anindya Sen as well as our discussants Céline Bonnet, Rodrigo Moita, Leonard Nakamura and Frank Verboven for comments. Lastly, we are grateful to the Editor, Co-Editor and an anonymous referee for useful comments and suggestions.

${ }_{\dagger}^{\dagger}$ Stockholm School of Economics. Email address: cristian.huse@gmail.com. Web: http://cristianhuse.webs.com. Correspondence address: Stockholm School of Economics, Box 6501, 11383 Stockholm, Sweden.

${ }^{\ddagger}$ Research Institute of Industrial Economics. Email address: nikita.koptyug@ifn.se. Correspondence address: Research Institute of Industrial Economics, Grevgatan 34, Box 55665, 10215 Stockholm, Sweden. 
JEL Classification Codes: C21, D12, D22, G32, G33, L62.

Key words: Administration, Automobiles, Bankruptcy effects, Brand loyalty, Bounds, Consumer reaction, Consumer response, Difference-in-differences, Durable goods, Financial distress, Treatment effects. 


\section{Introduction}

In a number of industries such as the automobile industry, both warranties and post-sales assistance are prevalent and of such great importance to consumers that these are yet another dimension over which carmakers differentiate their products (Cars.com 2011a, 2011b). As a result, whenever a company producing automobiles, or any other durable good, faces financial difficulties - bankruptcy in the extreme case - one might expect consumers to shy away from its products due to risks associated with the company ceasing to exist and post-sales services tied to the product becoming worthless (as modeled in, e.g. Titman 1984).

The importance of post-sales services to consumers make the auto industry well-suited for studying how consumers perceive and react to the financial difficulties of carmakers. The studies by Hammond (2013a) and Hortaçsu, Matvos, Syverson and Venkataraman (2013) have made use of these features and, perhaps unsurprisingly, found that that financial distress of a carmaker does affect the secondary car market; on average consumers are no longer willing to pay as much for a used car produced by a carmaker that starts experiencing financial difficulties.

To study how consumers react to financial difficulties and distress on the primary market, one has to establish among other things whether it is a carmaker's financial health that is affecting consumer behavior or vice-versa. In this study, we aim to resolve the issue of reverse causality by focusing on the effects of Swedish carmaker Saab's financial distress and filing for administration on the Swedish new passenger car market. ${ }^{1}$ Saab, originally a domestic Swedish carmaker whose products were praised by their admirers for the fine engineering and characteristic design, was facing financial ills due to the parent company's General Motors' (GM) own financial problems of late 2008. ${ }^{2}$ Following the financial aid package provided by the US Government to bail out GM in late 2008, it eventually became clear that Saab would not benefit from a rescue of its parent company. The terms of the emergency loan granted to GM were such that the money was to be used to save American jobs and other funds would have to be used to keep Saab operational (SvD 2008b). Due to these circumstances, we argue that Saab's financial situation was not a concern for

\footnotetext{
${ }^{1}$ Saab is known among car enthusiasts for (among other things) launching the first mainstream turbocharged car ever sold, the Saab 99 (Popular Mechanics 2008).

${ }^{2}$ As detailed below, supply-side related concerns were not a major concern in Saab's case.
} 
potential buyers until GM started experiencing its own financial troubles. Having lost the backing of GM in early 2009 after a strategic review, the financial difficulties facing Saab led the company to file for administration in February 2009. It was only months later that GM agreed on Saab's sale to a new owner with the financial backing of both the Swedish Government and the European Investment Bank (EIB). As a result, once a binding deal regarding the sale of Saab to Koenigsegg Group was signed in August 2009, Saab's administration came to an end.

Empirical Strategy We use vehicle registration-based data to study purchases of new Saab cars by private individuals in Sweden during the years 2006-2009. By doing so, we contribute to a better overall understanding of how consumers react to financial distress and on the impact of financial distress on a company. ${ }^{3}$

In our analysis, we take advantage of a key institutional setting of the Swedish new car market: Sweden being a small market, car dealers keep low inventory levels, so consumers typically order a car a few months in advance. This means that as long as Saab was producing cars, it would have been possible to order a car as before. Further, this results in very few episodes of sales or rebates from the part of carmakers or dealers, making the list prices we observe a much improved approximation to transaction prices than in most markets, e.g. the U.S. As a result, we are able to make use of both price and quantity information in our analysis.

Our identification relies on the credible exogeneity of GM's financial health to Saab product market performance but not to its financial one. That is, prior to filing for administration, Saab could count on the financial backing of GM, a large multinational conglomerate which did on several occasions inject funds into its subsidiary. However, this situation changed abruptly once GM applied for financial assistance from the US Government, which set as a precondition that US funds are only used to keep US jobs and could not be used to support Saab or other foreign brands.

To identify and quantify the impact of Saab's financial distress on consumer purchasing behavior, we use a difference-in-differences (DD) matching estimator whereby we compare the sales

\footnotetext{
${ }^{3}$ Although companies and the Swedish government purchase a significant share of new cars in Sweden, they do not necessarily have the same objectives as consumers when purchasing automobiles. For instance, the Swedish government has a mandate to buy environmentally friendly vehicles for non-emergency services.
} 
of Saab, the treatment group, to those of comparable cars on the Swedish market, the control group. We propose constructing our control group by matching Saab products to a set of close competitors according to observable product characteristics. ${ }^{4}$ More importantly, we propose a way to estimate treatment effects when both treated and untreated subjects are likely to be affected by the treatment. To do so, we propose economically-motivated bounds for the DD estimator we consider. The motivation for the bounds comes from the fact that our control group for Saab products consists of close substitutes to the treated subjects. The fact that there may be substitution from Saab products to the control group renders standard methods used in the treatment-effects literature unfit for our purposes (see Angrist and Pischke 2010 and Nevo and Whinston 2010 for a closely related exchange). For instance, in our application, substitution from the treatment to control group results in standard DD estimates being biased upward (in absolute terms), i.e. any consumer reaction to Saab's financial ills is likely to be overstated by the standard DD estimator. To account for this, we propose bounds for our DD matching estimator by assuming that the true effect lies between no - and perfect substitution between treatment and control groups.

One concern raised by our empirical strategy - the matching procedure in particular - regards how the size and composition of the control group affect the bounds we propose. That is, the method might give researchers excessive leeway, so that in the extreme case, the choice of the control group may determine the bounds to the DD effect. To address such concern, we provide conditions under which our bounds are either not substantially, or not at all, influenced by the choice of control group. First, a homogeneity condition whereby cross-price elasticities between the treated subject and products within a market segment are similar. Second, a dominance condition according to which the own-price elasticity of the treated subject dominates cross-price elasticities between itself and products in the same market segment, which in turn dominate crossprice elasticities between the treated subject and products in other market segments. Third, a symmetry condition whereby products in the treatment and control groups have sales of similar magnitudes. Under these conditions, the bounds become a function of own- and within-group cross-price elasticities of the marketed products. Such conditions are consistent with empirical findings for differentiated product markets (see Appendix B for an illustration) and allow the

\footnotetext{
${ }^{4}$ We also provide robustness checks using the synthetic matching methods of Abadie and Gardeazabal (2003).
} 
method to be applied within Industrial Organization and Antitrust settings.

Although one could think that the assumptions we impose would result in uninformative (i.e. overly wide) bounds, we show in our application that even without refining the bounds we obtain results pointing to a significant effect of Saab's financial distress on its sales.

Main Findings In contrast to previous findings for the used car market, we find limited evidence that prices of the Saab brand as a whole responded to its financial distress. As a result, we focus primarily on its sales. Doing so, we find ample evidence that consumers react to Saab's financial troubles; our most conservative results point to consumer reactions corresponding to a decrease of over 200 units sold by the Saab brand, as compared to the control group, a sizable 50 and 56 percent effect if compared to unconditional average sales of Saab which amount to 470 units per month. Given the ample evidence of the existence of a home-bias in both the International Trade and Industrial Organization literature, especially for the auto industry, see for instance Goldberg and Verboven $(2001,2005)$, one could think that such effects might be stronger for foreign brands operating in a given market. All in all, our estimates for the new car market are one order of magnitude larger than those previously obtained in the literature looking at the used car market.

The strength of our results leads us to explore alternative explanations for our findings. First, we focus on additional reasons - above and beyond the finance channel - that are likely to drive consumer reactions. In addition to documenting that are findings are unlikely to be driven by supply effects, we show that our results survive a number of robustness tests, including accounting for increased promotional activity of competing brands, news coverage, technological laggardness of Saab products and different treatment periods. In particular, our results are also obtained using different control groups.

Second, we consider the external validity of our results. The Swedish market is broadly comparable to other European markets (see e.g. Table 1 of Huse and Lucinda 2014 for details). For instance, ACEA (2015) reports that new passenger car registrations in Sweden are 32 vehicles/1000 inhabitants, roughly between those of Germany and France (38 and 27 vehicles/1000 inhabitants, respectively). Moreover, we have also considered the effect of financial distress on the sales of Opel products, the best-selling GM brand in Sweden. Our results suggests that any differences in the 
results of Opel and Saab are due to their different status in GM's restructured brand portfolio.

Contribution We contribute to a rich literature investigating the costs of financial distress and its effects on the product market and on firm performance. On the theoretical front, Titman (1984)'s results point to the major role played by decreases in demand as a result of financial distress. On the empirical front, there are conflicting views regarding how distressed companies respond, typically focusing on prices; while the studies of Chevalier (1995) and Matsa (2011) document that supermarket increase prices when in financial distress, Busse (2002) finds that firms in worse financial condition are more likely to start price wars in her study of the airline industry. More recently, Hammond (2013a) and Hortaçsu et al (2013) examine the used car market and find evidence of (single-digit) price reactions as a consequence of financial distress of a company. Our results suggest that the main channel whereby market participants react to financial distress is quantities, very much in the spirit of Titman (1984). Such reaction is significant both statistically and - at roughly $50 \%$ reduction in sales - economically. The limited evidence of price reactions in the case of the Saab brand to countervail the substantial decrease in quantities allows to estimate the loss in revenues of the distressed company, in contrast to previous literature.

Methodologically, we provide bounds derived using economic assumptions in a setting when standard reduced-form methods are unfit for use (Nevo and Whinston 2010). Initially, such bounds are obtained assuming that there is either no or full substitution between treatment and control groups. They can be moreover refined by assuming substitution patterns between products are well-behaved and consistent with empirical findings for many differentiated products markets.

The paper is organized as follows. Section 2 provides an overview of the market. Section 3 describes the data. Section 4 outlines the empirical strategy and Section 5 presents the results.

\section{Market}

\subsection{Overview}

Hosting two carmakers, Sweden is highly dependent on the automobile industry, which is key to employment, investments, exports and R\&D in the country. In fact, out of a population of 
roughly 9 million, some 120,000 are employed by the automobile industry which is responsible for over 10 percent of Swedish exports (BIL Sweden 2010). Moreover, Sweden is the second and first market for local brands Volvo and Saab, respectively (BIL Sweden 2010). Having originated in Sweden, Volvo and Saab were taken over by US carmakers, thus becoming brands within global car conglomerates Ford and GM, respectively.

While Volvo has been regularly on the top spot, commanding a market share of about 15 percent over the years, Saab has consistently been the 10th top selling brand in the Swedish market prior to administration, with a market share in the range 4-5 percent. This is consistent with previous evidence of a home-bias whereby consumers tend to favor domestic car brands (Goldberg and Verboven 2001). Other major carmakers in terms of sales include Toyota, Peugeot, Volkswagen and Ford, as reported in Table 1. Overall, the Swedish new car market is comparable to those of other European countries albeit having a preference for more powerful, heavier cars (see e.g. Huse and Lucinda 2014).

\section{INSERT TABLE 1 ABOUT HERE}

Car sales in the Swedish market peaked in 2007 and depressed considerably in June 2009 with the global recession. ${ }^{5}$ Even within the Swedish market, Saab had sold just over 6,000 units annually in the years prior to 2009 at which point sales declined more than for the other brands with Saab sales having fallen by 65 percent.

Throughout the years, Saab has produced few models which are praised by their admirers for the fine engineering and characteristic design. Its very size was one of its major hurdles, as the brand was unable to explore economies of scale well-known to exist in the automobile industry. Coupled with the fact that GM never fully integrated Saab into its portfolio of brands, the growing feeling over the years was that Saab was beginning to lag behind its competitors due to high development costs combined with low production levels.

\section{INSERT TABLE 2 ABOUT HERE}

\footnotetext{
${ }^{5}$ This period coincided with the green car rebate (GCR) between 2007 and 2009, which provided a transfer of 10,000 SEK (roughly USD 1,500) for consumers purchasing an environmentally friendly ("green") car. See Huse (2014) for a detailed description of the GCR.
} 
Table 2 compares a number of characteristics of Saab vehicles against those of other brands for years 2006-2009, providing difference-in-means tests between Saab and non-Saab vehicles. ${ }^{6}$ Typically, Saab models are less fuel-efficient, more expensive, heavier and more powerful than the average car sold in Sweden for each year in the sample. Notably, there are few statistically significant differences between Saab and control group vehicles. However, Saab does stand out in terms of horse power, producing significantly more powerful cars than those of the control groups. In particular, while (sales-weighted) CO2 emissions in the Swedish market followed a downward trend during the sample period, the effect was much less pronounced among Saab models, hinting that the brand was lagging in terms of technological development - although the observed differences are not statistically significant. Comparing the sales-weighted characteristics of Saab to those of closely competing models, we see that the average improvements that can be observed for the market as a whole are no longer as obvious for this sub-sample of vehicles. For instance, although fuel economy has been slightly better for competing models, no clear improvements in fuel economy have been made in comparison to the Saab products when looking at the entire sample period.

\subsection{Saab Automobile}

Saab Automobile became a fully-owned subsidiary of GM Europe in 2000, when GM purchased a 50 percent stake in Saab from Investor AB for USD 125 million (Investor AB 2000) after ten years of joint ownership. Saab was one of a total of twelve other brands owned by GM, but in 2008 it accounted for sales of roughly 100,000 units (Saab History, 2008) out of a total of 8.5 million units sold by GM worldwide (General Motors, 2009). As a result, it is highly unlikely that Saab may have played any role in GM's financial situation.

What is perhaps more striking is that, out of the twenty years of GM ownership, Saab only generated a profit in two, with GM consistently injecting money into its subsidiary (Dagens Industri, 2009c). ${ }^{7}$ That is, even if Saab arguably lacked the sales volume of close competitors such

\footnotetext{
${ }^{6}$ Although we have sales data from 2005, we look only at data starting from 2006 due to the construction of the control groups. See section 5.2 for details.

${ }^{7}$ Although justifications may have differed from one year to the next, GM did regularly inject funds into Saab. For instance, GM justified stepping in during August 2005 due to a weakening of the US dollar, high development costs and increased price competition from other brands (SvD 2008a).
} 
as Audi and BMW in global terms, it was consistently among the top ten best-selling brand in its main market (see Table 1). More importantly, Saab could very much count on continuous funding provided by GM to finance its operations. Thus, despite a less-than-stellar performance in the product market, it is unrealistic to think of the Saab brand as being in financial distress. ${ }^{8}$

Things were to change dramatically for Saab following the US financial package to rescue GM and Chrysler. When GM appealed for emergency aid to remain solvent in late 2008, the U.S. government's willingness to aid the automobile industry initially sparked hope for Saab whose future was becoming increasingly uncertain. However, GM made it clear that financial aid would not be provided to its European operations (Dagens Industri 2008a). That is, the terms of the emergency loan granted to GM were such that the money would be used to save American jobs and instead that other funds would have to be used to keep Saab going (SvD 2008b), at least until a strategic global overview had been conducted.

In early 2009 GM announced that Saab was to become a more independent company, in what was seen as a first step in preparing Saab for a future divestiture and a possible precondition for receiving financial aid from the Swedish government (Dagens Industri 2009a). On February 12th 2009, GM asked the Swedish government to back a SEK 5 billion loan from the European Investment Bank (SvD 2009a). ${ }^{9}$ Without the backing of either the Swedish government or GM, Saab was forced into filing for an emergency loan at the EIB on its own (TT News Agency 2008, 2009a). On February 17th 2009, GM presented its restructuring plan to the US Congress with Saab no longer being a part of its future strategy (SvD 2009b). On February 18th, GM announced plans to sell Saab and that if Saab were to remain solvent until a sale was completed, the company would require emergency loans from the Swedish government (TT News Agency 2009b)

On February 20th 2009, Saab officially filed for administration. ${ }^{10}$ While under administration,

\footnotetext{
${ }^{8}$ This suggests that Saab was in economic distress during a longer period but that any additional drop in performance due to GM's inability to continue to provide funding to Saab is primarily due to financial distress and not economic distress.

${ }^{9}$ This amounts to approximately USD 600 million at the then prevailing exchange rate of 8.42 SEK/USD.

${ }^{10}$ In Sweden, a company may file for bankruptcy or administration. Administration, legally speaking, is available for companies that are very likely to fail to fulfill their financial obligations in the short term but are deemed to have future potential. To be granted the related legal status, a company must apply with a court which may or may not grant administration status for up to one year. If a company is allowed to enter into administration, it is legally allowed to delay honoring legal obligations while at the same time being legally protected from debt collectors. Furthermore, during administration a company cannot be forced into bankruptcy. The period of administration
} 
it was expected that Saab would continue to operate, although there were concerns that sales would be depreciated further if worried consumers were to stop buying Saab products altogether. Production was interrupted for only one week, i.e. until until February 27th, when Saab was able to obtain liquid funds and pay outstanding fees (TT News Agency 2009c). ${ }^{11}$ GM started honoring credit lines open on Saab's behalf on March 2nd 2009 as it entered administration. As a result, key suppliers were able to resume operations and supply Saab with the necessary components to keep production open (Dagens Industri 2009b).

Despite the rumored interest of a number of companies, it took until May 292009 to find Saab a potential buyer - Swedish sports carmaker Koenigsegg, which went on to sign an intent to purchase Saab on June 15 (TT News Agency 2009d). Part of the deal was an expected government-backed loan of USD 600 million from the EIB and a strategic partnership with GM whereby it would supply Saab with engines and transmission systems (Saab AB 2009). On August 17 2009, GM and Koenigsegg Group, a consortium led by Koenigsegg, signed a binding deal regarding the sale of Saab. As a result, on August 19th 2009 Saab officially filed for an end to administration, which was granted on August 21st (TT News Agency 2009e).

\section{Data}

We combine administrative-based registration data with publicly-available car characteristics. The details are as follows.

Vehicle characteristics Product characteristics for years 2005-2009 are obtained from the consumer guide, the New Car Guide (Nybilsguiden), issued by the Swedish Consumer Agency (Konsumentverket). For every car model available on the Swedish market the information includes characteristics such as fuel type, engine power and displacement, number of cylinders, number ends after the court deems the company financially capable of continuing to operate.

${ }^{11}$ Anecdotal evidence also suggests that a large number of suppliers manufacturing components for Saab vehicles were poorly diversified in that many produced components were only suitable for use in Saab vehicles. This suggests that some smaller manufacturers may have gone out of business, since suppliers could not easily switch from supplying Saab with parts to another manufacturer. Despite this, we have found no accounts to suggest that Saab had difficulty in finding suppliers for manufacturing parts leading to supply problems of either the Saab 9-3 or $9-5$. 
of doors, gearbox type, weight, fuel economy ${ }^{12}$, CO2 emissions, vehicle tax and list prices. List prices, sticker prices or MSRPs (manufacturer's suggested retail prices) are set by manufacturers and are typically constant across geographic markets within a model-year. Given the difficulty in obtaining transaction prices, MSRPs have commonly been used in the literature, see e.g. Huse and Lucinda (2014) for a recent study of the Swedish market. Importantly, since Sweden is a small market, car dealers keep low inventory levels, so consumers typically order a car a few months in advance, which results in few episodes of sales or rebates from the part of carmakers or dealers, making the list prices we observe a much improved approximation to transaction prices than in most markets, e.g. the US.

Vehicle registrations Car registration data was provided by Vroom Stockholm, a consulting company. The data on privately-owned vehicles is recorded at the monthly frequency from January 2005 to December 2009. ${ }^{13}$ An observation is a combination of year, brand, model, engine size, fuel type (thus more disaggregated than the typical market level data set) and market segment.

Sweden being a small market, car dealers keep very low inventory levels, so much so that typically one has to order a car a few months in advance and make a deposit (anecdotal evidence is that delivery times can take from four weeks to four months). This results in very few episodes of sales or rebates from the part of carmakers and/or dealers. Moreover, if anything, we can expect transaction prices to be lower than list prices e.g. due to fire selling or retailer discounting, thus underestimating the treatment effect.

Combining vehicle datasets Given the different levels of aggregation, we merge characteristics and registration datasets by month-brand-model-fuel type and attribute the sales of all versions of a given model to its baseline characteristic specification.

Demand shifters We consider a number of alternative demand shifters; First, we include an indicator for the GCR period (from April 2007 to June 2009), since certain vehicles were eligible for a rebate. Second, we consider a measure of consumer confidence from the National Institute

\footnotetext{
${ }^{12}$ Fuel economy is measured in terms of city, highway and mixed driving, with testing conducted under a EUdetermined driving cycle and expressed in liters per 100 kilometers, or 100 cubic meters per $\mathrm{km}$ for gas (CNG) cars. $\mathrm{CO} 2$ emissions are measured in $\mathrm{gCO} 2 / \mathrm{km}$ under EU-determined driving conditions and mixed driving.

${ }^{13}$ Legally, the registration of a motor vehicle with the Swedish Transport Agency (Transportstyrelsen) must take place within ten working days of a change in vehicle ownership.
} 
for Economic Research (Konjunkturinstitutet). Consumer confidence is a leading indicator for the purchase of durable products, see Ludvigson (2004) for a survey and Friberg and Huse (2012) for an application to the demand for new automobiles. Finally, we include controls for new versions of existing products, so as to account for re-design, facelifts etc. of models in the control group, which are likely demand shifters. In order to determine which models within a control group have had a facelift or redesign, we proceeded by looking at photos in carmakers' websites and specialized magazines.

\section{Bounding the Treatment Effect}

We are interested in estimating whether consumers react to the financial distress of Saab. To establish a causal link between consumer behavior and Saab's financial health, we rely on the particular institutional setting of the market, whereby any measurable impact is in fact caused by the financial distress of Saab and not the prior behavior of consumers or suppliers, i.e. causality runs from the company's financial side towards the product market - something we discuss in more detail when defining the treatment period.

In order to identify and quantify the impact of Saab's financial distress on consumer purchasing behavior we use a difference-in-differences (DD) matching estimator. DD is commonly used to estimate the impact of a treatment or event on a predetermined treatment group or individual. The effect of the treatment is obtained by comparing the outcomes of the treated group with that of a carefully selected control group. The difference in post-treatment outcomes between the two groups measures the differential impact of the treatment itself. While one may indeed find differences in post-treatment outcomes between the treated and untreated (control) groups, the underlying cause of any such difference may be due to factors other than the treatment itself. To minimize the chance of factors other than Saab's financial distress being responsible for changes in consumer behavior, we construct control groups at the level of year-model-fuel type, e.g. a 2008 Saab 9-3 running on diesel, using matching techniques.

Given our particular setting, one valid concern is that since elements of the control group are close competitors to those in the treatment group, there is a potential mismeasurement in the 
effect of the treatment. This relates to an ongoing debate regarding the use of treatment-effects methods in Industrial Organization - especially merger analysis - see Angrist and Pischke (2010) and Nevo and Whinston (2010). One criticism of DD methods comes from the fact that treatment may affect not only the treatment group but also the control group. This effect is of special concern in a setting of strategic interactions among players. In our case, unlike the studies of Hammond (2013a) and Hortaçsu et al (2013), we focus on quantities instead of prices; whenever the sales of the treated group decrease those of the control group are likely to react in the opposite direction as consumers substitute from treatment group elements to control group elements. This reaction will be an indirect treatment effect of the treatment on the treated with a less than proportional increase occurring if some of the consumers opting not to buy an element of the treatment group also choose not to purchase an element of the control group. Hammond (2013b) faces a similar issue when studying the effect of automobile recalls on vehicle resale values: the fact that Toyota recalled some vehicles due to safety concerns may have had a positive impact on competing brands' resale values, as current Toyota users replace their vehicle or potential Toyota buyers switch to competing brands. Alternatively, there may have been a negative spillover as consumers may have switched to domestic brands altogether.

\subsection{Bounds and the Indirect Treatment Effect}

Although we cannot be sure of the extent of the indirect treatment effect or substitution looking only at aggregate data, we are able to say something about the true treatment effect if we are willing to consider the two most extreme scenarios regarding substitution from the treatment to control group. That is, that either all of the consumers that switch away from the treatment group substitute to the control group, or that none of the consumers substitute to the control group. Together, these two extremes will bound the true estimate, regardless of the true level of substitution. ${ }^{14}$ In our case, the observed control group sales are a combination of sales to consumers who would have purchased an element from the control group regardless of treatment

\footnotetext{
${ }^{14}$ For a rigorous analysis of the bounding of treatment effects in the presence of contaminated or corrupted data see Horowitz and Manski (1995), who show how to construct bounds for models in which one observes data that is composed of a true observation plus some noise.
} 
being applied to the treatment group and the consumers who decide to purchase an element in the control group as a consequence of treatment. ${ }^{15}$

Setup Assume a two-period difference-in-differences specification given by

$$
y_{i t}=\theta_{i}+\mu_{t}+T_{t} G_{i} \delta+u_{i t}
$$

where

$$
\theta_{i}=\theta+G_{i} \phi
$$

and

$$
\mu_{t}=T_{t} \mu
$$

The parameter $\theta$ measures the control group mean pre-treatment, $\mu$ measures the difference in control group means between pre- and post-treatment periods, $\phi$ measures the difference in means between treatment and control group pre-treatment. The time periods are denoted by $t=1,2$, $y_{i t}$ is the true outcome variable of both the untreated and treated groups, which are indexed by $i=c, \tau$, and $G_{i}$ takes on a value of one if the observation is a treated subject and zero otherwise, whereas $T_{t}$ takes on a value of one for observations falling within the treatment period and zero otherwise. The coefficient of interest is given by $\delta$ and measures the treatment effect. Further, assume that treatment is exogenous, that is, treatment is uncorrelated with the error term $u_{i t}$.

Assumption A1 The true post-treatment outcome variable for the control group is potentially biased by an indirect treatment effect $d$ given by the number of consumers having substituted from the treatment group. Formally, let us rewrite the model in (1) as

$$
y_{i t}^{*}=\theta_{i}+\mu_{t}+T_{t}\left(G_{i} \delta+\left(1-G_{i}\right) d\right)+u_{i t}
$$

\footnotetext{
${ }^{15}$ Related strategies have been pursued by Sallee (2011), who uses bounded treatment effects to measure the incidence of tax credits for the Toyota Prius.
} 
or more compactly as

$$
y_{i t}^{*}=\theta_{i}+\mu_{t}^{*}+T_{t} G_{i} \delta^{*}+u_{i t}
$$

where $\delta^{*}=(\delta-d), \mu_{t}^{*}=\left(\mu_{t}+T_{t} d\right)$ and following treatment, the control group outcome variable absorbs some unobservable non-random value $d$.

This assumption states that the sales of the control group we observe may be biased because consumers that would have bought a Saab product switched to a vehicle belonging to the control group. If we look at the expected outcome for the control group post-treatment, we have

$$
\begin{aligned}
E\left[y_{i t}^{*} \mid G_{i}=0, T_{t}=1\right] & =E\left[y_{i t} \mid G_{i}=0, T_{t}=1\right]+d \\
& =\theta_{c}+\mu_{2}+d
\end{aligned}
$$

where we see the outcome is biased by the indirect treatment effect $d$. Furthermore, we see that the OLS estimate of the treatment effect as given in (3) will be

$$
\delta^{*}=\delta-d
$$

that is, the estimated treatment effect $\delta^{*}$ will be a biased estimate of the true treatment effect $\delta$. The coefficient $\mu_{t}^{*}$ will analogously be biased but as this coefficient is not the main focus of our study we will only mention that bounds can also be derived for this coefficient in much the same way as we do below for the treatment effect $\delta$.

In our application, we expect $d$ to be positive because we believe there is likely to be a positive substitution effect away from Saab to the control group. That is, we believe the sales of the control group will be higher than they would otherwise have been, absent Saab's filing for administration.

Without loss of generality, let us also assume that the true treatment effect $\delta$ is non-positive, $\delta \leq 0$. That is, we are assuming ex-ante that Saab's sales are going to fall due to it's filing for administration. This assumption allows us to bound the indirect treatment effect $d$ in a natural 
and intuitive way, as will become clear with the next assumption.

Assumption A2 The indirect treatment effect $d$ is bounded

$$
\Delta_{L} \leq d \leq \Delta_{U}
$$

In particular, $0 \leq d \leq-\delta$.

Assumption A2 seems natural if, for instance, the object of interest is quantities or market shares; in this case, the indirect treatment effect can be bound by zero and, say, total sales. Implicit in this assumption are assumptions regarding substitution to the outside good: on the one extreme, we say that the average drop in Saab sales is entirely absorbed into the outside good $(d=0)$ whereas on the other extreme we say that no consumer chooses the outside good $(d=-\delta){ }^{16}$

Assumption A3 The control group consists of $K \geq 1$ equally weighted individuals. This implies that the outcome of the control group, $y_{c t}$, is the equally-weighted average of the $K$ individuals' outcomes, $y_{k t}$. Formally, assume

$$
y_{c t}=\frac{1}{K} \sum_{k} y_{k t}
$$

Within the control group, assume that each element $k$ absorbs $d_{k}$ units from the treatment group in the post-treatment period, with $d=\sum_{k} d_{k}$. Formally, with an equally-weighted control group the biased outcome is given by

\footnotetext{
${ }^{16}$ The outside good is for example a car model outside of the closest competitors of Saab used to form the control group, or to postpone the purchase of a car into the non-foreseeable future. While Huse and Lucinda (2014) provide structural evidence that the share of the outside good did not change during the period of the GCR, which encompasses that of Saab's administration, we prefer to be conservative and further control for a number of demand shifters likely to affect demand more locally, see Section 3.
} 


$$
\begin{aligned}
y_{c t}^{*} & =\frac{1}{K}\left(y_{1 t}+T_{t} d_{1}+\ldots+y_{k t}+T_{t} d_{k}\right) \\
& =\frac{1}{K} \sum_{k} y_{k t}+\frac{1}{K} T_{t} \sum_{k} d_{k} \\
& =y_{c t}+\frac{1}{K} T_{t} d \\
& =y_{c t}+T_{t} d^{*}
\end{aligned}
$$

which consists of the average of all individual control group elements, $y_{c t}$, pre-treatment (when $T_{t}=0$ ), and the average of these outcomes, $y_{c t}$, together with the average of the indirect treatment effect given by $d^{*}=\frac{1}{K} d$, post-treatment (when $T_{t}=1$ ). This comes from the fact that although the control group elements absorb $d$ units in sum, the group as a whole absorbs on average $d^{*}=\frac{1}{K} d$.

Assumption A3 is illustrated by the following example.

Example In our setting, the control group consists of Saab's close competitors with the control group outcome being a simple average of each of the competitors' outcomes. For instance, if Volvo sells 100 units of its V70 and 150 units of its V50 post treatment, a control group consisting only of these two models will have an average outcome of 125 units. If we assume that Saab loses 10 units in sales post treatment which are fully absorbed by the V70 and the V50, for instance with all 10 units being absorbed by the V70, the control group outcome will instead be 130 - the average of 110 and 150. That is, the control group outcome is the sum of the true outcome $y_{c t}=125$ and the average of the total number of units absorbed by the V70 and the V50 post treatment, namely $d^{*}=\frac{10}{2}=5$.

As established above, the estimated treatment effect is given by $\delta^{*}=\delta-d$, where $d$ is the indirect treatment effect. If we use a control group of equally weighted individuals, then from assumption A3 we see that the indirect treatment effect is instead $d^{*}=\frac{1}{K} d$ giving the estimated treatment effect as $\delta^{*}=\delta-\frac{1}{K} d$. From this relationship we see that $\delta \cong \delta^{*}$ as $K$, the number of control group elements, grows large, i.e. the bias vanishes as $K$ increases. However, it is also important 
to emphasize the trade-offs involved in choosing the size of the control group, since an overly large control group would consist of subjects that will no longer be substitutes of those in the treatment group. In our setting, the more models we include in the control group, the more likely we are to include vehicles which can no longer be seen as close substitutes to Saab vehicles. In the most extreme case, one could include all models available on the market while on the other one could include only one. As discussed below, under mild conditions one obtains that the bounds depend on the the own-price elasticity of the treatment group and the cross-price elasticities between elements of the treatment and control groups. This is intuitive since the indirect treatment effect is the result of the substitutability between elements in the treatment and control groups. Before, Proposition 1 below derives more general properties of the bounds.

Proposition 1 Let Assumptions A1 and A2 hold. Then the true treatment effect $\delta$ is bounded. Formally,

$$
\delta^{*}+\Delta_{L} \leq \delta \leq \delta^{*}+\Delta_{U}
$$

Proof: See Appendix.

This proposition states that although we do not know the true treatment effect $\delta$ we can nevertheless say something about its magnitude if we are willing to make assumptions about the bounds of the indirect treatment effect $d$. For instance, if we assume that there is no bias, that is $\Delta_{L}=\Delta_{U}=0$, then the estimated treatment effect $\delta^{*}$ is going to be equal to the true treatment effect $\delta$. If on the other hand we have a strictly positive bias $\left(\Delta_{U}>\Delta_{L}>0\right)$, Proposition 1 tells us that given a non-positive treatment effect, $\delta \leq 0$, we will underestimate the true treatment effect by at least $\Delta_{L}$ and at most $\Delta_{U}$.

Corollary 1 (Bounded EW Estimator) Let assumptions A1, A2 and A3 hold. Then the true treatment effect is bounded by

$$
\delta^{*} \leq \delta \leq \frac{K}{K+1} \delta^{*}
$$


Alternatively, for any constant level of substitution $\lambda \in[0,1]$ the true treatment effect is given $b$

$$
\delta=\frac{K}{K+\lambda} \delta^{*}
$$

Proof: See Appendix.

Although Proposition 1 makes the general statement that we are able to find bounds on the true treatment effect $\delta$ even in the presence of an indirect treatment effect $d$, Corollary 1 provides specific bounds for the true treatment effect $\delta$ given our assumptions on the bounds of the indirect treatment effect $d$. The lower bound is simply the case when there is no indirect treatment effect and the true treatment effect $\delta$ equals the estimated treatment effect $\delta^{*}$. Given our previous assumption that the outcome of the control group is an average of the control group individuals' outcomes, the upper bound is a function of how many elements we include in our control group with the interval narrowing as the number of control group elements $K$ increases. However, we need not assume that there is either perfect or no substitution, assuming instead that substitution is given by some fixed fraction $\lambda \in[0,1]$ of the true treatment effect. Although less conservative, such an assumption would allow us to fully recover the true treatment effect through the relationship given by $\delta=\frac{K}{K+\lambda} \delta^{*}$.

Corollary 2 (Bounded EW Estimator Variance) For any constant fraction $\lambda \in[0,1]$ of consumers in the treatment group switching to the control group and constant size of the control group $K \geq 1$, the variance of the treatment effect estimator can be written as

$$
\operatorname{Var}(\hat{\delta})=\left[\frac{K}{K+\lambda}\right]^{2} \operatorname{Var}\left(\hat{\delta^{*}}\right)
$$


Proof: See Appendix.

One implication of an indirect treatment effect is that the variance of the estimated coefficient $\delta^{*}$ will also be incorrect, as seen from (6). The result of Corollary 2 parallels that of Corollary 1 in that if we were to assume, or know, the true fraction $\lambda$ of consumers substituting from the treatment to the control group we would be able to correct the variance of the estimate in order to do correct inference.

Corollary 3 (Standardized EW Estimator) The standardized estimate of the treatment effect remains unchanged by the bias $d$, that is

$$
\frac{\hat{\delta}^{*}}{\sqrt{\operatorname{Var}\left(\hat{\delta}^{*}\right)}}=\frac{\hat{\delta}}{\sqrt{\operatorname{Var}(\hat{\delta})}}
$$

Proof: See Appendix.

Corollary 3 states that although there may be an indirect treatment effect that over - or underestimates the true treatment effect, because the indirect treatment effect merely inflates the estimate and it's variance, the two effects exactly cancel out leaving T-statistics unchanged. Although we construct $95 \%$ confidence intervals using block bootstrapping to avoid small sample issues of heteroskedasticity and autocorrelation corrected estimators of standard errors, Corollary 3 states that we could have used regular T-statistics had we had a robust estimate of the coefficient standard errors. ${ }^{17}$

\subsection{Refining the Bounds}

Our analysis so far has obtained bounds without imposing much economic structure, the exception being the existence of an outside good. In what follows, we will make assumptions on substitution patterns between products in order to obtain bounds which satisfy two conditions. First, the

\footnotetext{
${ }^{17}$ Our choice of the block bootstrap is expected to improve on standard bootstrap methods such as in Horowitz and Manski (2000) due to its accounting of potential autocorrelation in the data.
} 
bounds should be more informative than those obtained above. ${ }^{18}$ Second, the bounds should not depend on the size of the control group. That is, to the extent possible, the bounds should be determined by the data rather than by the researcher.

Our analysis relies on bounding the substitution parameter between treatment and control groups, $\lambda$, known in the literature as the diversion ratio and widely used in antitrust analysis (Shapiro 1996, Werden 1998). Assuming without loss of generality that $K^{\prime}$ elements of the control group are in the same market segment as the treated subject and $K^{\prime \prime}$ in other market segments $\left(\right.$ so $\left.K^{\prime}+K^{\prime \prime}=K\right)$, one can write

$$
\lambda:=\frac{\Delta q_{C}}{\Delta q_{T}}=-\frac{\varepsilon_{C T}}{\varepsilon_{T T}} \frac{q_{C}}{q_{T}}=-\sum_{i=1}^{K} \frac{\varepsilon_{i T}}{\varepsilon_{T T}} \frac{q_{i}}{q_{T}}=-\frac{\sum_{i}^{K^{\prime}} \varepsilon_{i T} q_{i}}{\varepsilon_{T T} q_{T}}-\frac{\sum_{i}^{K^{\prime \prime}} \varepsilon_{i T} q_{i}}{\varepsilon_{T T} q_{T}}
$$

where $q_{T}$ and $q_{C}$ are total sales of treatment and control groups, $\varepsilon_{i T}$ is the cross-price elasticity between the treatment group and element $i$ of the control group, $\varepsilon_{T T}$ is the own-price elasticity of the treatment group and $\varepsilon_{C T}$ is the cross-price elasticity of the control group with respect to prices of the treatment group. ${ }^{19}$

To investigate how the substitution parameter changes as a function of the size and the composition of the control group, we need the following assumptions.

Assumption E1 (Dominance) The own price elasticity of the treatment group dominates the sum of the cross-price elasticities between elements of the treatment and control groups,

$$
\left|\varepsilon_{T T}\right| \geq \sum_{i=1, i \neq T}^{K} \varepsilon_{i T}
$$

Assumption E1, which applies only to elements of the treatment and control groups, is implied by an elasticity matrix with a dominant diagonal. ${ }^{20}$ Intuitively, it holds if consumers decide not to purchase any product given that treatment occurred. In our application, this amounts to a

\footnotetext{
${ }^{18}$ Recall that $\lambda \in[0,1]$ and $\lambda=0$ is the standard DD case.

${ }^{19}$ We assume throughout that the treatment group has a single element for the sake of tractability.

${ }^{20}$ The dominant diagonal condition is given by $\left|\varepsilon_{j j}\right| \geq \sum_{j \neq i}\left|\varepsilon_{j i}\right|, \forall i, j=1, \ldots, J$, where $J(>K)$ is the number of inside products, i.e. all products on the market.
} 
consumer not purchasing a new vehicle due to the financial ills of Saab, for instance.

Assumption E2 (Substitutability) Let the cross-price elasticities between a product and its substitutes in the same market segment dominate its cross-price elasticities with respect to products in other market segments. Moreover, let the latter be negligible, in the sense that substitution is mostly within a market segment. Since $K^{\prime}$ elements of the control group are in the same market segment and $K^{\prime \prime}$ elements of the control group are in other market segments, one can write

$$
\sum_{i=1, i \neq T}^{K} \varepsilon_{i T}=\sum_{i=1, i \neq T}^{K^{\prime}} \varepsilon_{i T}+\sum_{i=1, i \neq T}^{K^{\prime \prime}} \varepsilon_{i T} \approx \sum_{i=1, i \neq T}^{K^{\prime}} \varepsilon_{i T}
$$

Assumption A2 posits the existence of different market segments, which is typical of differentiated products markets such as the automobile industry. What is more, while the closer the substitution between two products, the higher their cross-price elasticities, Assumption E2 requires that there is virtually no substitution between products in different market segments. Economically, this is consistent with the fact that consumers choose among products which are somewhat similar in characteristics space. In particular, it is consistent with estimates coming from (onelevel) nested logit demand models, where cross-price effects within a nest are substantially larger than cross-price effects between nests, which are often negligible. ${ }^{21}$

Assumption E3 (Homogeneity) Assume the market under consideration is segmented, with homogenous cross-price elasticities within and across market segments denoted by $\varepsilon_{H}$ and $\varepsilon_{L}$, respectively, with the homogeneous elasticities satisfying ${ }^{22}$

$$
\sum_{i=1, i \neq T}^{K} \varepsilon_{i T} \leq K^{\prime} \varepsilon_{H}+K^{\prime \prime} \varepsilon_{L}
$$

\footnotetext{
${ }^{21}$ In Appendix B, we report estimates of nested logit specifications which are consistent with the above assumption, see Table B1. For instance, in Specification 5 the average within-nest (cross-nest) cross-price elasticity is $0.06(0.01)$ with standard deviation $0.12(0.01)$.

${ }^{22}$ Formally, $\varepsilon_{H}$ denotes the cross-price elasticity between the treatment group and elements of the control group in the same market segment as those in the treatment group whereas $\varepsilon_{L}$ denotes the cross-price elasticity between the treatment group and elements of the control group in different market segments.
} 
Homogeneity of the elasticities is not crucial, but facilitates obtaining analytical results. Examples of functions satisfying the inequality in Assumption E3 are averages or maxima of the elasticities within a segment. Assumption A3 could be further generalized by assuming richer patterns (consistent with, say, a multi-level nested logit model), but this is unlikely to add much in terms of insight. ${ }^{23} 24$

Assumption E4 (Symmetry) Products in the control and treatment groups have sales of similar magnitudes, $q_{i} \approx q_{T} \approx \tilde{q}, \forall i \in C G$.

Assumption E4 is also made for the sake of tractability. Alternatively, one could assume that sales of the treated product are a scaled version of the typical element of the control group, but this would add little in terms of insight.

In what follows, we bound the substitution parameter $\lambda$ using the above assumptions and then provide the associated bounds to the DD effect.

Proposition 2 Let assumptions E1-E4 hold. Then

$$
\lambda \leq-K^{\prime} \frac{\varepsilon_{H}}{\varepsilon_{T T}} \leq 1
$$

From Proposition 2, the diversion ratio $\lambda$ is affected only by the number of products in the control group in the same market segment as the product in the treatment group, in addition to the corresponding own- and cross-price elasticities. Interestingly, $\frac{\partial \lambda}{\partial K}=-\frac{\varepsilon_{H}}{\varepsilon_{T T}}>0$ meaning that even if lambda never reaches 1 , it increases - at a rate determined by the ratio of own- and cross-price elasticities - with the number of within-nest elements belonging to the control group, $K^{\prime}$.

\footnotetext{
${ }^{23}$ For instance, in a two-level nested logit model would have cross-price elasticities within a subgroup, between different subgroups of the same groups and between different groups.

${ }^{24}$ Table B1 in Appendix B reports findings consistent with the assumption of homogeneity, i.e. cross-price elasticities within a segment have the same magnitude and are typically clustered around their mean.
} 
Corollary 4 Let the assumptions in Proposition 2 hold. Moreover, let the elements in the control group and the market segment of the treated subject coincide $\left(K^{\prime}=K\right)$. Then the DD effect can be bounded as follows ${ }^{25}$

$$
\delta^{*} \leq \delta \leq \frac{\varepsilon_{T T}}{\varepsilon_{T T}-\varepsilon_{H}} \delta^{*}
$$

where $\delta^{*}$ is the naive (OLS) DD estimate.

Within the framework of a one-level nested logit model, the assumptions above imply that those products in the control group are within the same nest as the product in the treatment group. From Corollary 4, once one assumes that $K^{\prime}=K$, a sensible assumption if one is to believe that the control group should only contain elements in the same market segment as the treated subject, the relation between the biased DD estimate and the true one depends on own- and cross-price elasticities. ${ }^{26}$ Alternatively, given the naive (OLS) DD estimates $\delta^{*}$, the upper bound of the true DD effect is obtained by multiplying the naive estimate by a term consisting of price elasticities.

\section{Empirical Analysis}

\subsection{Treatment Period}

The DD estimator quantifies the effect of a treatment - Saab's financial distress in our application

- on an outcome by comparing the average change over time in such outcome for treatment and

\footnotetext{
${ }^{25}$ We have also derived results where we replace E1-E3 with a stronger dominance condition $\left(\right.$ E1'), $\rho\left|\varepsilon_{T T}\right| \geq$ $\sum_{i=1, i \neq T}^{K} \varepsilon_{i T}, \rho \in(0,1]$. Under E1' and E4, we obtain $\lambda \leq \rho$, i.e. the diversion ratio is majorated by the dominance parameter, $\rho$. This implies that $\delta \in\left[\delta^{*}, \frac{K}{K+\rho} \delta^{*}\right]$, i.e. as in the previous section, the bound narrows as the size of the control group grows large. While the bounds still depend on the size of the control group, the result allows comparing the relative importance of the dominance parameter and the size of the control group, with a stronger dominance parameter (lower $\rho$ ) resulting in a narrower interval for the DD effect. Moreover, comparing the latter result with the one in the text stresses the price to be paid in terms of assumptions to obtain bounds which do not depend on the size of the control group. The results are available from the authors upon request.

${ }^{26}$ Note, however, that the cross-price elasticity $\varepsilon_{H}$ likely changes with the size of the control group if it is not the case that $K^{\prime}=K$. For instance, by leaving out of the control group one element of the same market segment as the treated subject, one would be affecting the cross-price elasticity; arguably, this impact is more likely to be felt if $\varepsilon_{H}$ is taken to be the average cross-price elasticity than the maximum cross-price elasticity.
} 
control groups. This definition of treatment poses a problem of defining a specific point in time when the treatment was administered to the treatment group. Financial distress is generally not something that occurs instantaneously, being rather the consequence of poor financial conditions of a company over a certain, often prolonged, period of time. Not all companies with a poor financial situation can be construed as financially distressed. Instead, only once a certain threshold is crossed can a company realistically be defined as being financially distressed. One such threshold, if a little extreme, is the filing of a company for bankruptcy or administration; once a company files for bankruptcy or administration, as Saab did in February 2009, little doubt can remain as to whether the company is in financial distress or not. Alternatively, one could argue that what really triggers financial distress in Saab's case are GM's financial troubles, which were made public in November 2008 or when GM officially applied for emergency financial aid in December 2008.

The end of treatment for Saab is less of a controversy: having filed for administration, Saab was not liquidated but continued to operate under administration until the Swedish Courts ruled it was out of administration on August $212009 .^{27}$

In what follows, we define the treatment period to start when GM's financial problems become public, that is November 2008, and to end in August 2009. This treatment window yields the more conservative estimates of the treatment. In particular, our reported estimates are more conservative than those resulting from a treatment period starting in February 2009.

One natural concern is that Saab's poor sales performance started due to Saab's own financial issues that either did, or did not, influence GM's financial situation. However, recall from Section 2 that it is highly unlikely that any financial issues Saab may have had would have affected GM, mainly due to Saab being much smaller. Moreover, Saab only turned a profit on two out of the twenty years under GM ownership, thus consistently counting on GM's funds during this period. That is, despite its sub-par operating performance, one cannot claim that Saab was in financial distress.

Another concern is that there were other events during, or around, the treatment period which

\footnotetext{
${ }^{27}$ This means that the Court which had access to all of Saab's internal financial information, and granted Saab its legal administration status also deemed the company healthy enough to continue operating. Not only did the court deem Saab strong enough to continue operating but the ruling was arguably credible enough to restore buyers' confidence in the brand.
} 
may have had a direct impact on Saab sales. We have tried to capture any event, which we have not mentioned directly, by collectively combining news into indices and using these as additional control variables in our robustness checks. We believe that this allows us to directly control for any events that occurred to Saab before or after treatment which may have had additional impacts on the sales of Saab.

\subsection{Constructing Control Groups}

Choosing a suitable control group with which to compare the outcome of the treated group is largely dependent on the treatment group. In the current setting, the treatment group is the carmaker Saab (and its products) while the treatment is that of being in financial distress.

To quantify the impact of Saab's financial distress we need to construct a control group for each of Saab's products. Since consumers wish to purchase a car based on a fairly specific set of needs, an adequate control group should consist of vehicles catering to the same consumer needs as Saab models. That is, a control group should contain models which are close competitors to a given Saab product in characteristic space (design, market segment, engine size etc.) and evolve in a similar manner over time. ${ }^{28} 29$

One extreme case is to include only the single closest competitor of a given product in the control group. However, this would leave the control group potentially exposed to idiosyncratic events related to the very model included in it. On the other hand, having too many models in the control group would wash out the effects local to the market category a given Saab model belongs to. ${ }^{30}$ In other words, there is a clear trade-off regarding the size/composition of the control group.

To construct control groups we consider a market with $J$ products and $K$ characteristics denoted by $\chi_{k j}, j=1, . ., J ; k=1, \ldots, K$, typically assumed exogenous in the demand literature. To make characteristics of different magnitudes comparable we standardize each characteristic, denoted $\chi_{1 j}^{0}$,

\footnotetext{
${ }^{28}$ We make sure that no models from other brands owned by General Motors are included in any of the control groups used.

${ }^{29}$ Matching only on observable characteristics however means that those which are unobserved are not directly accounted for. If unobservable characteristics consist primarily of brand - or model- reputation then these are unlikely to vary greatly over time (as pointed out in e.g. Nevo (2001)).

${ }^{30} \mathrm{~A}$ further technical complication is that if you rebalance control groups annually with only a few elements, any differences in the magnitudes of sales may cause jumps in the sales.
} 
subtracting it from its the mean and dividing the demeaned characteristic by its standard deviation. For product $j$ the vector of standardized product characteristics is given by $\chi_{j}^{0}=\left(\chi_{1 j}^{0}, \ldots, \chi_{K j}^{0}\right)^{\prime}$. With the above notation set, we need to define a distance between products $i$ and $j$ in characteristic space to identify the closest competitors of each Saab product. One intuitive and convenient measure is the (weighted) Euclidean distance defined as

$$
\partial_{i j}=\left[\left(\chi_{i}^{0}-\chi_{j}^{0}\right)^{\prime} W^{-1}\left(\chi_{i}^{0}-\chi_{j}^{0}\right)\right]^{1 / 2}
$$

where $W$ is a weighting matrix potentially allowing for different weights according to the relevance of characteristics. ${ }^{31}$ Essentially, product $i$ will be identified as a close competitor of the treated (Saab) product $j$ whenever the distance between these two products is less than or equal to a threshold level $\partial^{*}$. In our setting, we choose $\partial^{*}$ such that each Saab product has a control group consisting of 10 competing products. A similar approach is used by Ashenfelter and Hosken (2008) in their study of consumer goods prices following mergers whereby the authors construct control groups out of "private label", or store brand, products that are closest in characteristic space to the products owned by merging parties. ${ }^{32}$

Control Group Composition We construct control groups for both gasoline and diesel versions of Saab's two models, the 9-3 and the 9-5. ${ }^{33}$ To make it into the control group, competitors have to be in the same market segment, run on the same fuel and be close to a specific Saab model in terms of its technical characteristics. ${ }^{34}$ Control groups are rebalanced every year using data from the previous year only, so as to avoid forward-looking biases and account for product entry and exit -

\footnotetext{
${ }^{31}$ Here we use an equal weighting scheme when calculating the Euclidean distances between different products.

${ }^{32}$ The above strategy relates to two approaches commonly used in economics, namely the distance-metric (DM, see Pinkse, Slade and Brett 2002) and the matching estimator (Cochran and Rubin 1973, Rosenbaum and Rubin 1983, Abadie and Gardeazabal 2003). DM essentially views products as a unique combination of characteristics, so substitution patterns across products are spatially determined, i.e. are determined by the relative proximity between products in characteristic space. This allows replacing a multidimensional set of characteristics with a summary statistic thereof, thus bypassing curse of dimensionality issues.

${ }^{33}$ Due to the small number of models available and the common technology (the Otto cycle engine), we coded vehicles able to operate on both gasoline and ethanol as gasoline. This is consistent with the empirically observed fact that substitution occurs mostly between gasoline and gasoline/ethanol cars, see Huse and Lucinda (2014) for additional evidence of this substitution.

${ }^{34}$ More precisely, within a market segment, e.g. sedan, and fuel, e.g. diesel, we use continuous variables such as engine power (horsepower, $\mathrm{HP}$ ), engine size (cubic centimeters, $\mathrm{cm}^{3}$ ), weight (kilograms, $\mathrm{kg}$ ), emissions $(\mathrm{gCO} / \mathrm{km})$, mixed fuel economy $(l / 100 \mathrm{~km})$ and list price (SEK).
} 
see Table 3 for the control groups of models 9-3 and 9-5. ${ }^{35}$ As discussed in the Appendix, results are robust to changes in the size and composition of the control group. While we report results using equally-weighted elements of the control group, sales-weighted elements yield similar qualitative results. Although there exists some degree of attrition in the control groups, it amounts to a small share of the models from year to year. As a further robustness check, we perform the main analysis with control groups that are not rebalanced, but instead retain their 2006 composition throughout the entire sample period, with similar results.

\section{INSERT TABLE 3 ABOUT HERE}

Control groups for the Saab 9-3 and Saab 9-5 versions are displayed in Table 3. As reported in Panel A, the main competitors of the Saab 9-3 running on gasoline across the years are the Skoda Superb, the Toyota Avensis and the VW Jetta. Other close competitors include models such as the Audi A4 and the Mazda 6. The results for the diesel version of the Saab 9-3 differ only slightly from those of the gasoline one; besides the models above, the Honda Accord, the Kia Magentis and the Peugeot 407 also often appear as competitors to the model.

Being larger than the Saab 9-3, it is no surprise that some of the models in the control group of the Saab 9-5 are also slightly larger than those in the control groups for model 9-3. For instance, besides the Skoda Superb, which also appears as a close competitor to the Saab 93, now models such as the Audi A6 (which is larger than the Audi A4) and the Hyundai Sonata also appear as close competitors to the Saab 9-5. ${ }^{36} 37$

Our approach is also closely related to the synthetic matching technique of Abadie and Gardeazabal (2003), who propose constructing a control group with elements weighted in a way to provide the best possible match between the treatment and control groups, pre-treatment. Although we

\footnotetext{
${ }^{35}$ While using characteristics from the same period rather than lagged ones does somewhat change the composition of the control groups, the results remain qualitatively very similar. Using models from the previous (as opposed to current) year arguably reflects more accurately the information set available to competitors when deciding about their own product lines for a given year, thus being preferred in our analysis.

${ }^{36}$ In our analysis, we have not allowed products of any GM brand to enter the control group, but did not constrain the presence of models produced by Chrysler. As a result, one Dodge (a subsidiary of Chrysler) product enters the control group. As a robustness check, we also perform our analysis excluding it from the control group, with marginal changes to the results.

${ }^{37}$ Although the control groups contain cars that may differ somewhat from a Saab product, there are very few statistically significant differences between the average Saab and average control group vehicle as reported in Table 2 .
} 
apply these synthetic matching methods in Section 6.1, we conduct our main analysis using control groups constructed as described above for the following reasons. First, recall that the car market witnesses a high number of products at any given point in time and episodes of entry, exit and facelift of products, all of which are likely to alter the consumer's perception of a product. Second, the demand for automobiles often manifests itself through shifts in demand for particular market segments, e.g. minivans, SUV's; thus, we believe that our weighting scheme is more likely to capture changing trends within the industry as a whole, rather than the trends of the individual control group elements.

\subsection{A First Look at the Data: Identification}

To assess the appropriateness of the DD analysis, we argue that absent treatment, the sales of Saab and the control group would have evolved in a similar manner. Formally, this amounts to testing the parallel trends assumption between treatment and control groups. First, notice that despite the noisiness, the sales of the Saab brand tend to follow the same pattern as that of the control group in the years prior to its filing for administration, as displayed in Panel A of Figure 1. In particular, the seasonal patterns are well pronounced for both groups. Starting from early 2009, Saab's sales are strongly affected whereas those of the control group follow an upward trend. Despite its magnitude, this discrepancy is short-lived - as early as mid-2009 the sales of Saab once again follow very closely those of the control group, in what coincides with the signature of Saab's purchase intent by Koenigsegg. ${ }^{38}$

\section{INSERT FIGURE 1 ABOUT HERE}

When decomposing the Saab brand figures at the model level, it becomes apparent that the behavior of Saab is driven mostly by its best-selling 9-3 model. In particular, although less pronounced for the 9-5 model, the pre-administration sales of both models follow closely those of their control groups, with sales of both models typically below the 100-unit threshold for most of the

\footnotetext{
${ }^{38}$ Although one could argue that this period also coincides with the end of the GCR, a policy which arguably benefited Saab due to its emphasis on gasoline/ethanol flexible fuel vehicles, a segment where Saab operated, its importance as compared to the end of administration is of second order. In fact, Huse and Lucinda (2014) shows that Swedish and high-end German brands did not benefit from the GCR. Nevertheless, our conservative choice is to still explicitly control for the GCR in our empirical specifications.
} 
administration period. Moreover, for all Panels in Figure 1, the sales of the treatment group are notable more volatile than those of the control groups. The smoothness in the sales of the control group are a direct consequence of the averaging of the sales of a number of products. However, we still fail to reject the null hypothesis of parallel trends between sales of treatment and control groups in the pre-treatment period, the key identifying assumption in the DD setting. In order to check whether this assumption is satisfied, we estimate a triple difference specification to assess the parallel trends assumption. More specifically, we interact a time trend with the treatment group and a dummy for the pre-treatment period.

\section{INSERT TABLE 4 ABOUT HERE}

Table 4 reports results for the Saab brand in Column 1, for the Saab 9-3 in Column 2 and for the Saab 9-5 in Column 3. For each case we consider the specification with the full set of controls, i.e. the GCR indicator, the consumer confidence measure and the interaction of product introduction and month fixed-effects. Additionally, in Section 6.1 we provide robustness checks using synthetically constructed groups as in Abadie and Gardeazabal (2003) whereby sales of the treatment group are replicated as closely as possible using the weighted sales of all other models. In this setting, the treatment and control group sales are very closely related pre-treatment but

fall for Saab in the treatment period. All these results lend support to the finding that, absent treatment, the sales of Saab and the control groups would have evolved in a similar manner, thus lending credence to the DD analysis we perform.

\subsection{Results}

To quantify consumer response to Saab's financial distress, we estimate DD regressions using sales as the dependent variable. We estimate such regressions both for the Saab brand as a whole and for its products separately.

\section{INSERT TABLE 5 ABOUT HERE}

Table 5 reports results for the Saab sales as compared to the control groups defined above, both for Saab as a brand as well as for the Saab 9-3 and the Saab 9-5 separately. To construct 
the overall brand level control group we first construct control groups for each individual Saab model-fuel combination, as noted above, and then aggregate these into a single brand level control group. Our benchmark specification is given by

$$
y_{i t}^{*}=\theta_{i}+\mu_{t}^{*}+T_{t} G_{i} \delta^{*}+x_{i t}^{\prime} \beta+u_{i t}
$$

where $t=1, \ldots, T$ are time periods, $y_{i t}^{*}$ are sales of treated (the Saab brand, a Saab 9-3 or a Saab 9-5 model, depending on the specification) and untreated groups, $G_{i}$ takes on a value of one if the observation is a treated subject and zero otherwise, whereas $T_{t}$ takes on a value of one for observations falling within the treatment period between November 2008 and August 2009 and zero otherwise, and $x_{i t}$ is a set of controls including fixed effects for the Green Car Rebate, month interacted with the number of new car models introduced a given year as well as a consumer confidence index. ${ }^{39}$ The DD estimator is given by $\delta^{*}$ and the model is estimated using ordinary least squares.

Columns 1 through 3 in Table 5 report results that differ with respect to treatment group used. DD coefficients are negative and significant throughout. The table shows the upper and lower bounds, $\bar{\delta}$ and $\underline{\delta}$ respectively which correspond to the estimated end-points of the inequality given by equation (5). If we are to assume perfect substitution, that is $\lambda=1$, then the true treatment effect would be correctly estimated by $\bar{\delta}$ whereas, if $\lambda=0$, or no substitution, then the true treatment effect would instead be correctly estimated by $\underline{\delta}^{40}$ The confidence intervals reported are $95 \%$ block bootstrapped confidence intervals obtained by block bootstrapping five hundred samples. We choose block bootstrapping in order to account for potential serial correlation in the errors terms, something earlier applications of the DD applications were criticized for not doing (Bertrand, Duflo and Mullainathan 2004). Although another alternative would be to use some form of standard errors corrected for heteroskedasticity and autocorrelation in the residuals, it has been suggested that these perform poorly in small samples. See the Appendix for additional

\footnotetext{
${ }^{39}$ One reason to include month fixed-effects is to account for potential difference between list and transaction prices.

${ }^{40}$ By proposition 2, the refined bounds may be narrower than the bounds assuming perfect or no substitution, as the nature of demand may significantly restrict the possible values of $\lambda$. To be conservative, however, we choose not to present the refined bounds.
} 
details and robustness checks.

Column 1 reports results of the specification for sales of the Saab brand as a whole. The treatment effect is bounded between -261.06 and -237.33 units, and is statistically significant at the 95 percent significance level. Given unconditional average monthly sales of 470 units between 2005 and late 2008, these results suggest a drop in the sales of Saab products of between 50 and 56 percent.

Columns 2 and 3, report a more disaggregated analysis focusing on Saab models 9-3 and 9-5, respectively. Since the 9-3 was Saab's best-selling product during the sample period, it is not surprising that it suffers the bulk of consumer reactions: while column 2 estimates are in the range of a 150-200 unit reduction in sales, those in column 3 are closer to a 50 unit decrease. Column

2 estimates for the Saab 9-3 suggest a treatment effect in the range between -204.30 and -185.73 units - a drop of between 61 and 67 percent given unconditional average monthly sales of 304 units between 2005 and late 2008 .

The DD results for model 9-5, reported in column 3 of Table 5, follow a path similar to that of the Saab 9-3 with a treatment effect bounded between -57.17 and -51.97 units. Given unconditional average monthly sales of 151 units between 2005 and late 2008, these results suggest a drop in the sales of Saab products of between 34 and 38 percent. A lower decline in the sales Saab 9-5 may be due to the Saab 9-5 being even older than the Saab 9-3 in terms of technology and because of this having a more loyal following from consumers.

All in all, consumer responses are not only statistically but also economically significant with the bounds providing evidence that, even in the worst case of full substitution towards the control group, consumers did react to the financial ills of Saab.

\subsection{Supply Effects}

One important challenge faced in the analysis of the effects of financial distress on firm performance is disentangling demand from supply effects. For instance, in the automobile industry a firm in financial difficulties may fire employees or cut production in order to improve revenues or better utilize production capacity. Even if the producer's actions were to remain the same, the dealers 
that sell the cars on to consumers may choose to stop transacting the cars because of the risk that at some point consumers stop purchasing the car altogether and the dealer is left with an initially expensive asset that becomes worthless. Further, suppliers of parts used in manufacturing may choose to stop supplying to firms in financial distress making it more and more difficult to keep production levels constant. All of these scenarios would potentially affect the supply of cars available for purchase and lead to a drop in sales - not because consumers do not want to buy the car but because they simply cannot.

In Sweden, unlike for example in the United States, dealers do not keep a large inventory with consumers instead having to order the exact vehicle they want to buy. This means that as long as Saab continued producing cars, consumers would still be able to go to a dealer and order the car that they wanted to buy with the dealer not being exposed to the risk of initially having to buy the vehicle and then being unable to sell it at a later point in time. ${ }^{41}$

Moreover, despite production at Saab being halted during the period it was under administration, this happened for only a single week in February 2009. Production was halted as Saab was unable to pay Swedish customs import duties for parts arriving from overseas suppliers. As soon as Saab had obtained liquid funds to pay the import duties, production resumed with no other interruptions taking place in 2009. ${ }^{42} 43$ Additionally, we have found no evidence that inventories of already manufactured Saab cars dwindled and were unable to cover demand. Furthermore, as seen from Figure 1, both the Saab 9-3 and 9-5 saw sales improving slightly towards the summer of 2009 with, for instance, the sales of the Saab 9-5 reaching levels better than those seen in early 2008. This suggests that there was enough of a supply to satisfy consumers once their demand improved.

Analysis of Vehicle Prices To support the above analysis, we perform a difference-in-differences analysis comparing the list prices of Saab cars to those of a control group to assess whether there

\footnotetext{
${ }^{41}$ See Huse and Lucinda (2014) for a more detailed description on the ordering of cars in Sweden.

${ }^{42}$ Although it was noted in the Swedish media that certain smaller suppliers did end up going bankrupt, we found no further evidence regarding issues with Saab not being able to manufacture cars because suppliers had stopped supplying parts.

${ }^{43}$ As an additional robustness check, we test whether the list prices of Saab vehicles changed as compared to control group. These are included in the Appendix.
} 
was any reaction in prices from the part of Saab. ${ }^{44}$ Table 6 reports separate results for Saab as a brand and for its models 9-3 and 9-5 using two different control groups. ${ }^{45}$ First, we use the standard control groups described above for the sake of consistency with the remaining of our analysis. Second, we perform a robustness check whereby we construct control groups containing all products in the same market segment as the Saab products.

\section{INSERT TABLE 6 ABOUT HERE}

The results in Table 6 document a lack of response in prices for Saab as a whole and for model 9-3, see Columns 1 and 2, respectively. However, the same does not hold for model 9-5, see Column 3. The reason why the significance of the price reactions for Saab 9-5 do not translate into price reactions for Saab as a whole is the small share of sales commanded by model 9-5 within the Saab brand. These results, hold also for our alternative definition of control group, compare Columns 1 and 4, 2 and 5, 3 and 6 .

Our interpretation of the above findings is as follows. In the case of the Saab 9-3, its supply curve is largely flat - inelastic to changes in quantities - due to the very fact that such model was the leading product of the Saab brand. In contrast, the supply curve of the already dated Saab 9-5 was upward-sloping, with the company accepting to lower its price in order to make up for, say, the lack of technology improvements and the dated layout. ${ }^{46}$

The fact that we find no significant difference between Saab prices and the prices of other cars may be due to prices being mismeasured, leading to an underestimated effect. We do not believe that our results are driven by attenuation bias but rather that the results correctly reflect that Saab's list prices did not change significantly as compared to that of other cars.

All in all, the reactions we document - no statistical evidence of price reactions for the Saab brand as a whole coupled with a roughly $50 \%$ reduction in sales - show the large economic impact of financial distress on the revenues (and thus profits) of a company.

\footnotetext{
${ }^{44}$ Since vehicles are effectively ordered in the Swedish market, there is little room for bargaining upon the purchase of a new vehicle, making list prices (Manufacturer Recommended Sale Prices, MRSPs) a good proxy for actual transaction prices in the new vehicle market, see Huse and Lucinda (2014) for details.

${ }^{45}$ Recall that that model 9-3 is the best-selling Saab product, commanding about $80 \%$ of the brand sales.

${ }^{46}$ See the Supplementary Appendix for a discussion of the technological lagardness of Saab's products.
} 


\section{Robustness}

This section reports selected robustness tests used to assess the maintained assumptions of the analysis above. The Supplementary Appendix reports results of a number of additional robustness checks.

\subsection{Synthetic Control Groups}

We examine whether our main results are robust to constructing a control group according to the synthetic matching methodology of Abadie and Gardeazabal (2003).

The synthetic control method allows estimating the effect of a treatment when a single unit (Saab, in our case) is exposed to such treatment. It consists of a data-driven methodology to construct synthetic control units based on a convex combination of untreated units which approximates the characteristics of the treated unit. For instance, in the case of Saab one would intuitively expect that the synthetic control group would consist of vehicle models which closely compete with Saab, due to their reputation or observable characteristics such as size. Such models would be weighted in a way that the combination mimics as closely as possible the behaviour of Saab sales pre-treatment in order to conduct inference for the post-treatment period.

Despite being somewhat similar, a few key distinctions exist between the construction of control groups presented in Section 5, and that presented in Abadie and Gardeazabal (2003). Whereas we construct control groups by matching Saab products to close competitors using only car characteristics, restricting these to the 10 closest competitors, the method of Abadie and Gardeazabal (2003) allows choosing the control group so as to synthetically match both the sales and car characteristics of the control group as closely as possible to that of the treatment group in the pre-treatment period.

We conduct the robustness check by constructing three types of synthetic control groups, namely (i) using only car characteristics; (ii) using only car sales; and (iii) using both car characteristics and sales in order to make these results comparable to the ones presented in the main analysis - see Appendix C for details. Furthermore, we also redo the exercise for another GM brand, Opel, in order to determine whether other GM brands also experienced similar effects of 
financial distress as those observed in Saab.

Results of Synthetic Matching We construct synthetic control groups based on each of the three methods described above focusing on Saab's most popular model, the Saab 9-3. The matching is carried out using all 90 competing products available before 2009 that were within the same market segments, excluding other Saab products. ${ }^{47}$ As the control group elements are no longer weighted equally, and as there is a much larger number of control group elements, we shall assume that substitution between the treatment and control group is not an issue and estimate a DD specification without taking substitution into account.

\section{INSERT TABLE 7 ABOUT HERE}

From Specifications 1 and 2 in Table 7, we see that when comparing the sales of the Saab 9-3 to those of a synthetic control group constructed using only standardized and equally-important product characteristics, the results are very similar to the main results where we construct control groups using proximity in characteristic space as the criterion for choosing the elements of the control group. Perhaps this is unsurprising as there are only a few differences in how the two control groups are constructed; the methodology of Abadie and Gardeazabal (2003) assigns weight by replicating the characteristics of the treated product as closely as possible from the entire universe of competing products, whereas the methodology presented in this paper equally weights the elements that are closest in characteristic space.

\section{INSERT FIGURE 2 ABOUT HERE}

As seen from the top panel of Figure 2, the synthetic control group does not perfectly replicate the sales of treated products in the pre-treatment period as information regarding sales is excluded in the construction of the synthetic control group. As a direct comparison, the bottom panel of Figure 2 shows sales for the Saab 9-3 and a synthetic control group which is constructed in order to replicate the sales of the Saab 9-3 in the pre-treatment period. We see that the sales of the Saab 9-3 and the sales of the synthetic control group are very similar in the pre-treatment period, diverging significantly in the post-treatment period. This is confirmed by the regression results presented

\footnotetext{
${ }^{47}$ As with the main results, other GM brands are not allowed to be part of the control group.
} 
in Specifications 3 to 5 of Table 7, from which we can conclude that there are no statistically significant pre-treatment differences in outcomes between the treatment group and the control group but that there is a significant difference in post-treatment outcomes. ${ }^{48}$

Distress of Other General Motors Brands We also perform the synthetic matching exercise using another GM brand, Opel, the best-selling GM brand in Sweden. Similarly to Saab, Opel may itself have experienced a decline in sales due to the financial distress of GM. Whereas Saab's future was uncertain, largely due to GM's announcement that Saab was to be made independent and that it would no longer be a part of GM, Opel was to remain an integral part of GM as part of a slimmer GM. Despite this, as GM's future as whole was uncertain in late 2008, this uncertainty may have affected the sales of Opel. However, if consumers were to have stopped buying Opel cars due to uncertainty of the financial situation of GM, we should expect the effect to have at least partly disappeared with the effective bailout of GM in June 2009. ${ }^{49}$

\section{INSERT FIGURE 3 ABOUT HERE}

Looking at Specifications 5 and 6 in Table 7, we see that sales of Opel's best selling model, the Opel Astra, do also decline as compared to their synthetic control groups. However, what is more important, see Figure 3, sales of the Opel Astra recover almost immediately following the bailout of GM. The above findings are consistent with our line of reasoning in several dimensions. First, Saab was not the only brand to suffer a decline in sales due to GM's failing financial health. That is, consumers, do react to the perception that a company is in ill financial health.

Second, the effects were different for Opel and Saab due to their differential status in GM's restructured brand portfolio - while Saab was to be made independent, Opel was to remain one of GM's core brands.

Finally, the fact that Opel sales rebound so markedly from June 2009 suggests that supply was not a large factor driving the decline in Opel sales. That is, the effect was in most part demanddriven. This fact lends additional credibility to our arguments that the decline in Saab sales was not caused by supply effects but rather demand effects.

\footnotetext{
${ }^{48}$ As before, we cannot reject the parallel trends assumption pre-treatment.

${ }^{49}$ For the sake of comparison, we will assign the same treatment window for Opel as that of Saab. Restricting the window to coincide with GM's financial distress - that is November 2008 to June 2009, strengthens the results.
} 


\subsection{Negative Spillovers}

In this paper, we focus on positive spillovers from Saab, a treated firm, to the control group. It may also be the case Saab's financial distress spilled over onto the control group or the whole market in a negative way, inducing buyers to postpone the purchase of a car or not purchasing a car altogether. Assuming that the potential number of total buyers is stable across time, then, controlling for other factors, any decline in the total number of control group cars sold during the post-treatment period would indicate that buyers of control group cars may also have been affected.

To test whether there was any negative spillover from Saab's financial distress, we proceed as in Huse \& Lucinda (2014) who estimate whether the market share of the outside good in Sweden increased due to the Green Car Rebate (GCR). We estimate the spillover effect by regressing the total number of control group cars sold during our sample period on our baseline control variables and a post-treatment period dummy. A significant post-treatment period dummy would suggest that after controlling for general time trends, seasonality and economic confidence, there was an additional change in sales due to there being a treatment effect spilling over from Saab onto the control group.

\section{INSERT TABLE 8 ABOUT HERE}

As reported in Column 1 of Table 8, we find a point estimate which indicates that, during the treatment period, there was an additional decline of roughly 27 units for the Saab brand control group. For the Saab 9-3 control group, the point estimate in Column 2 suggests that during the treatment period there were roughly 15 fewer units sold and for the 9-5 control group roughly 7 fewer units sold as seen in Column 3. However, none of these point estimates are statistically significant. Further, we conduct the same analysis for the entire market in Column 4 of Table 8 and find that although there was an indication of there being roughly 700 fewer units sold during Saab's treatment period, this estimate is also statistically insignificant. These results suggest that if there were negative spillovers due to Saab's financial distress, such effects were quite small. 


\subsection{Placebo Tests}

We conduct two sets of placebo tests to assess whether there were significant differences between treatment and control groups, pre-treatment. The first placebo test considers a treatment period between January 2008 and October 2008, that is, a treatment period of exactly the same length, exactly prior to the beginning of the treatment period used in the paper. The second placebo test considers a treatment period between between February and November 2007, thus ending one year prior to the start of the main treatment window used.

\section{INSERT TABLE 9 ABOUT HERE}

For each case we consider the specification with the full set of controls, i.e. the GCR indicator, the consumer confidence measure and the interaction of product introduction and month fixed-effects. Table 9 reports results for the Saab brand in Column 1, for the Saab 9-3 in Column 2 and for the Saab 9-5 in Column 3. The results consistently show the lack of significant differences between treatment and control groups, pre-treatment. Although insignificant, the results of the first placebo test suggest there may have been a decline in Saab sales in the months prior to treatment.

\subsection{Additional Robustness Tests}

We have conducted a number of additional robustness checks; we have explored whether the decline in Saab sales was the result of increased promotional activity on behalf of other brands trying to use Saab's situation to increase their own sales. To account for the potential that some brands may have increased their promotional activity in order to gain market share at the time Saab was experiencing financial distress we assume that the two models within each control group that had the highest percentual increase in sales between 2008 and 2009 would have been the models that saw a large increase in promotional activity. We drop these two models and re-estimate the models with the remaining eight models in each control group and we find that the treatment effects are smaller but still statistically significant.

Further, we look at the extent to which news coverage and technological laggardness can explain the drop in sales observed for Saab and its products. We have also constructed control groups 
using fewer or more elements, leaving the control groups fixed rather than rebalancing them on a yearly basis. We find that the results are quantitatively and qualitatively similar to the main specifications.

We have also looked at different time-frames for the treatment window and run Granger Causality tests to test exogeneity of treatment whereby lagged sales are able to predict the probability of being treated. We find that increasing the treatment window length increases our results but that lagged sales are not able to predict being treated in the future.

A full description and discussion of the robustness checks can be found in the Supplementary Appendix.

\section{Conclusion}

In this paper, we examine how consumers respond to the financial problems of Swedish carmaker Saab. Our empirical strategy consists of matching Saab products to a set of close competitors and performing a difference-in-differences analysis. We match the Saab products to other vehicles based on product characteristics and aggregate up to construct the control group for the Saab brand.

On the methodological front, we show that substitution from Saab products to those of the control group will lead to an overestimation of the true treatment effect. Assuming that all consumers substituting away from Saab either purchase a vehicle in the control group or opt for the outside good, we show that the true treatment effect can be bounded. What is more, since the substitutability between products is at the root of the overestimation of the DD effect, we provide conditions under which the bounds depend on own- and cross-price elasticities of the products considered and not on the number of control group elements.

Our bounds provide a way to look at difference-in-differences methods in settings where treatment affects both treatment and control groups, an issue recently discussed by Angrist and Pischke (2010) and Nevo and Whinston (2010) in the context of Industrial Organization and Antitrust, but which should also be applicable to other fields.

Our findings are robust to changes in the treatment window, control groups and control vari- 
ables. This lends further support to the conclusions of previous studies according to which consumers do worry about void warranties, difficulties in securing spare parts and qualified service.

While the qualitative results of this paper are similar to that of the studies by Hammond (2013a) and Hortaçsu et al (2013), we focus on the primary market. Given both institutional and empirical evidence that prices in the Swedish new vehicle market are well-behaved, our analysis allows to infer how a firm will be affected by financial distress. In fact, we find a significant drop in Saab's monthly sales amounting to 50-56 percent of average pre-treatment sales, which will likely be larger for firms not benefiting from home-bias, as seems to be the case of Saab. 


\section{References}

[1] Abadie, A. and J. Gardeazabal (2003), The Economic Costs of Conflict: A Case Study of the Basque Country. The American Economic Review 93 (1), 113-132.

[2] ACEA (2015), The Automobile Industry Pocket Guide 2015/2016.

[3] Angrist, J. D. and J-S. Pischke (2010), The Credibility Revolution in Empirical Economics: How Better Research Design is Taking the Con Out of Econometrics. Journal of Economic Perspectives 24, 3-30.

[4] Ashenfelter, O. and D. Hosken (2008), The Effect of Mergers on Consumer Prices: Evidence From Five Selected Case Studies. NBER Working Paper No. 13859.

[5] Berry, S., J. Levinsohn and A. Pakes (1995), Automobile Prices in Market Equilibrium. Econometrica $63(4), 841-890$.

[6] Bertrand, M., E. Duflo and S. Mullainathan (2004), How Much Should We Trust DifferencesIn-Differences Estimates? The Quarterly Journal of Economics 119 (1), 249-275.

[7] BIL Sweden (2010), Swedish Motor Industry Facts (Svensk Fordonsindustri Faktablad).

[8] Busse, M. (2002), Firm Financial Condition and Airline Price Wars. RAND Journal of Economics 33 (2), 298-318.

[9] Cars.com (2011a), Making Sense of New-Car Warranties (Online at http://www.cars.com/go/advice/)

[10] Cars.com (2011b), Compare Manufacturer Warranties (Online at http://www.cars.com/go/advice/)

[11] Chevalier, J. A. (1995), Do LBO Supermarkets Charge More? An Empirical Analysis of the Effects of LBOs on Supermarket Pricing. Journal of Finance 50 (4), 1095-1112.

[12] Cochran, W. G. and D. B. Rubin (1973), Controlling Bias in Observational Studies: A Review. Sankhya Series A 35 (4), 417-446. 
[13] Dagens Industri (2008a), Government prepares billion SEK loans to the Swedish car industry. (Publ. online on 8/12/2008 at http://di.se/Artiklar/2008/12/8/4460/Regeringen-forberedermiljardlan-till-svensk-bilindustri/)

[14] Dagens Industri (2008b), New GM rumors - Saab could be affected. (Publ. online on 30/10/2008 at http://di.se/Artiklar/2008/10/30/4550/Nya-GM-rykten-Saab-kan$\operatorname{drabbas} /$ )

[15] Dagens Industri (2009a), How Saab is being prepared for a sale. (Publ. online on 13/1/2009 at http://di.se/Artiklar/2009/1/13/3853/Sa-forbereds-Saab-for-forsaljning/)

[16] Dagens Industri (2009b), GM is paying the debt. (Publ. online on 2/3/2009 at http://di.se/Artiklar/2009/3/2/10079/GM-betalar-skulderna/)

[17] Dagens Industri (2009c). This has happened. (Publ. online on 2/12/2009 at http://www.di.se/artiklar/2009/12/2/saab-detta-har-hant-/)

[18] Friberg, R., and C. Huse (2012), How to Use Demand Systems to Evaluate Risky Projects, with an Application to the Automobile Industry. Mimeo.

[19] General Motors (2009), GM Announces 2008 Global Sales of 8.35 Million Vehicles. (Online at http://www.gmignitionupdate.com/media/us/en/gm/)

[20] Goldberg, P. K. and F. Verboven (2001), The Evolution of Price Dispersion in the European car market. Review of Economic Studies 68, 811-848.

[21] Goldberg, P. K. and F. Verboven (2005), Market Integration and Convergence to the Law of One Price: Evidence from the European Car Market. Journal of International Economics 65, 49-73.

[22] Hammond, R. G. (2013a), Quantifying Consumer Perception of a Financially Distressed Company. Journal of Business 65 Economic Statistics 31(4), 398-411.

[23] Hammond, R. G. (2013b), Sudden Unintended Used-price Deceleration? The 2009-2010 Toyota Recalls. Journal of Economics 6 Management Strategy 22 (1), 78-100. 
[24] Horowitz, J. L. and C. F. Manski (1995), What Can Be Learned About Population Parameters when the Data Are Contaminated. Working Paper.

[25] Horowitz, J. L. and C. F. Manski (2000), Nonparametric Analysis of Randomized Experiments With Missing Covariate and Outcome Data. Journal of the American Statistical Association, 95 (449), $77-84$.

[26] Hortaçsu, A., Matvos, G., C. Syverson and S Venkataraman (2013), Indirect Costs of Financial Distress in Durable Goods Industries: The Case of Auto Manufacturers. The Review of Financial Studies 26(5), 1248-1290.

[27] Huse, C. (2014), Fast and Furious (and Dirty): How Asymmetric Regulation May Hinder Environmental Policy. Working paper.

[28] Huse, C., and C. Lucinda (2014), The Market Impact and the Cost of Environmental Policy: Evidence from the Swedish Green Car Rebate. Economic Journal 124, 393-419

[29] Investor AB (2000), GM/Opel exercise option in Saab Automobile. Official press statement made on January 31. (Online at http://ir.investorab.com/files/press/investor/investor-press2000-01-31-111700-sv.pdf)

[30] Ludvigson, S. C. (2004), Consumer Confidence and Consumer Spending. Journal of Economic Perspectives 18, 29-50.

[31] Matsa, D. A. (2011), Competition and Product Quality in the Supermarket Industry. Quarterly Journal of Economics 126 (3), 1539-1591

[32] Nevo, A. (2001), Measuring Market Power in the Ready-to-Eat Cereal Industry. Econometrica $69(2), 307-342$

[33] Nevo, A. and M. W. Whinston (2010), Taking the Dogma Out of Econometrics: Structural Modeling and Credible Inference. Journal of Economic Perspectives 24, 69-82.

[34] Pinkse, J., M. Slade, and C. Brett (2002), Spatial Price Competition: A Semiparametric Approach. Econometrica 70, 1111-1153. 
[35] Popular Mechanics (2008), Top 10 Turbocharged Cars of All Time. (Online at http://www.popularmechanics.com/cars/news/vintage-speed/4296068)

[36] Saab AB (2009), official press statement.

[37] Sallee, J. (2011), The Surprising Incidence of Tax Credits for the Toyota Prius. American Economic Journal: Economic Policy 3, 189-219.

[38] Shapiro, C. (1996), Mergers with Differentiated Products. Antitrust, 23-30.

[39] SvD (2008a), GM hunts for a merger. (Publ. online on 13/10/2008 at http://www.svd.se/gmjagar-samgaende)

[40] SvD (2008b), GM not allowed to save Saab. (Publ. online on 10/12/2008 at http://www.svd.se/gm-far-inte-radda-saab)

[41] SvD (2008c), New Saabs postponed. (Publ. online on 7/11/2008 at http://www.svd.se/nyasaab-forsenas)

[42] SvD (2009a), GM wants Swedish money. (Publ. online on 11/2/2009 at http://www.svd.se/gm-vill-ha-svenska-pengar)

[43] SvD (2009b), Saab is not part of the future portfolio. (Publ. online on 17/2/2009 at http://www.svd.se/saab-finns-inte-med-i-framtida-portfoljen)

[44] Swedish Consumer Agency (2004-2009), Nybilsguiden (The New Car Guide).

[45] Titman, S. (1984), The Effect of Capital Structure on a Firm's Liquidation Decision. Journal of Financial Economics 13, 137-151.

[46] TT News Agency (2008), Saab seeks support from EIB. (Publ. online on 17/2/2009 at http://www.svd.se/saab-soker-stod-av-eib)

[47] TT News Agency (2009a), GM to sell Saab Automobile. (Publ. online on 18/2/2009 at http://di.se/Artiklar/2009/2/18/9080/GM-saljer-Saab-Automobile/ ) 
[48] TT News Agency (2009b), Toll stops Saab's deliveries. (Publ. online on 25/2/2009 at http://di.se/Artiklar/2009/2/25/9801/Tullen-stoppar-Saabs-leveranser/ )

[49] TT News Agency (2009c), Koenigsegg forms conglomerate. (Publ. online on 15/6/2009 at http://di.se/Artiklar/2009/6/15/18102/Koenigsegg-bildar-koncernbolag/)

[50] TT News Agency (2009d), Saab's restructuring officially ended. (Publ. online on 21/8/2009 at http://di.se/Artiklar/2009/8/21/22126/Saabs-rekonstruktion-formellt-avslutad/ )

[51] TT News Agency (2009e), GM leaning towards Spyker. (Publ. online on 10/12/2009 at http://di.se/Artiklar/2009/12/10/2102/-GM-lutar-at-Spyker/ )

[52] Werden, G. J. (1998), Demand Elasticities in Antitrust Analysis. Antitrust Law Journal 66 (2), 387-394. 


\section{Tables and Figures}

\begin{tabular}{cc|ccccccc} 
& & \multicolumn{7}{c}{ Sales Rank } \\
\hline \hline \multirow{4}{*}{ Panel A: Market Shares } & & $(1)$ & $(2)$ & $(3)$ & $(4)$ & $(5)$ & $\ldots$ & $(10)$ \\
& Year & Volvo & Toyota & Peugeot & Volkswagen & Ford & $\ldots$ & Saab \\
& 2006 & $15.38 \%$ & $9.38 \%$ & $9.45 \%$ & $7.63 \%$ & $5.93 \%$ & $\ldots$ & $5.25 \%$ \\
& 2007 & $17.42 \%$ & $9.47 \%$ & $9.32 \%$ & $7.15 \%$ & $5.80 \%$ & $\ldots$ & $4.11 \%$ \\
& 2008 & $12.44 \%$ & $10.99 \%$ & $8.48 \%$ & $8.35 \%$ & $5.48 \%$ & $\ldots$ & $3.74 \%$ \\
& 2009 & $14.77 \%$ & $12.29 \%$ & $5.69 \%$ & $6.88 \%$ & $5.69 \%$ & $\ldots$ & $1.66 \%$ \\
\hline \hline \multirow{4}{*}{ Panel B: Sales } & $2006-2009$ & $15.20 \%$ & $10.34 \%$ & $8.46 \%$ & $7.50 \%$ & $5.74 \%$ & $\ldots$ & $3.87 \%$ \\
& Year & Volvo & Toyota & Peugeot & Volkswagen & Ford & $\ldots$ & Saab \\
& 2006 & 21,468 & 13,091 & 13,198 & 10,648 & 8,281 & $\ldots$ & 7,330 \\
& 2007 & 26,345 & 14,323 & 14,104 & 10,814 & 8,779 & $\ldots$ & 6,218 \\
& 2008 & 14,144 & 12,492 & 9,642 & 9,493 & 6,233 & $\ldots$ & 4,247 \\
& 2009 & 14,414 & 11,999 & 5,549 & 6,718 & 5,554 & $\ldots$ & 1,619 \\
\hline
\end{tabular}

Table 1: Annual market shares and sales volumes of the five most frequently purchased car brands in Sweden together with tenth best selling brand for 2006-2009, Saab. Panel A: Annual market shares of the five most frequently purchased car brands in Sweden together with tenth best selling brand Saab; Panel B: Annual sales volume of the five most frequently purchased car brands in Sweden together with the tenth best selling brand Saab. 


\begin{tabular}{|c|c|c|c|c|c|c|c|}
\hline & & Fuel Economy & List Price & Weight & Engine Power & Engine Size & CO2 Emission \\
\hline & Year & $(\mathrm{l} / 100 \mathrm{~km})$ & $(\mathrm{SEK})$ & $(\mathrm{kg})$ & $(\mathrm{HP})$ & $\left(\mathrm{cm}^{3}\right)$ & $(\mathrm{g} / \mathrm{km})$ \\
\hline \multirow{4}{*}{ Panel A: All Vehicles excl. Saab } & 2006 & 7.08 & $184,612^{* * *}$ & $1,361^{* * *}$ & $121^{* *}$ & $1,724^{*}$ & $171^{*}$ \\
\hline & 2007 & $6.75^{* *}$ & $192,696^{* * *}$ & $1,380^{* * *}$ & $127^{* * *}$ & $1,732^{* * *}$ & $165^{*}$ \\
\hline & 2008 & $6.45^{* * *}$ & $184,001^{* * *}$ & $1,344^{* * *}$ & $120^{* * *}$ & $1,630^{* * *}$ & $157^{* * *}$ \\
\hline & 2009 & $6.15^{* * *}$ & $191,630^{* * *}$ & $1,370^{* * *}$ & $122^{* * *}$ & $1,623^{* * *}$ & $151^{* * *}$ \\
\hline \multirow{4}{*}{ Panel B: Control Group Vehicles } & 2006 & 7.39 & 221,898 & 1,486 & 140 & 1,876 & 180 \\
\hline & 2007 & 7.10 & 226,679 & $1,497^{*}$ & 147 & 1,900 & 175 \\
\hline & 2008 & 7.31 & 234,628 & $1,501^{*}$ & $148^{* * *}$ & $1,893^{* *}$ & 178 \\
\hline & 2009 & 7.63 & 243,914 & 1,515 & $150^{* * *}$ & 1,927 & 184 \\
\hline \multirow{4}{*}{ Panel C: Saab Vehicles } & 2006 & 7.76 & 228,029 & 1,517 & 147 & 1,870 & 188 \\
\hline & 2007 & 7.88 & 241,819 & 1,549 & 168 & 1,942 & 193 \\
\hline & 2008 & 8.02 & 249,122 & 1,560 & 178 & 1,970 & 195 \\
\hline & 2009 & 7.63 & 246,135 & 1,559 & 178 & 1,968 & 185 \\
\hline
\end{tabular}

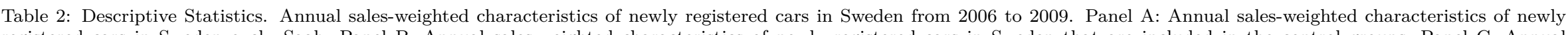

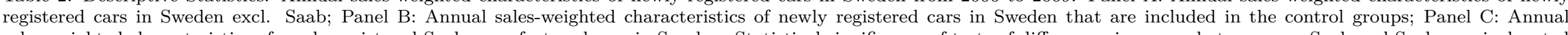

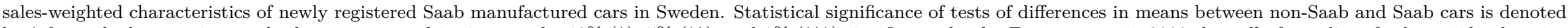

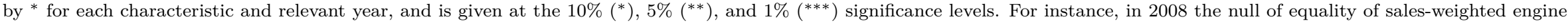
power between Saab (178 HP) and the control group (148 HP) is rejected at the $1 \%$ significance level. 


\begin{tabular}{|c|c|c|c|c|c|}
\hline & & \multicolumn{2}{|c|}{ Saab 9-3 } & \multicolumn{2}{|c|}{ Saab 9-5 } \\
\hline & Year & 2008 & 2009 & 2008 & 2009 \\
\hline \multirow{12}{*}{ Panel A: Gasoline } & 1 & Audi A4 & Alfa Romeo 159 & Alfa Romeo 159 & Alfa Romeo 159 \\
\hline & 2 & Dodge Avenger & Dodge Avenger & Audi A4 & Audi A6 \\
\hline & 3 & Honda Accord & Honda Accord & Audi A6 & Dodge Avenger \\
\hline & 4 & Kia Magentis & Kia Magentis & Dodge Avenger & Honda Accord \\
\hline & 5 & Mazda 6 & Peugeot 407 & Hyundai Sonata & Hyundai Sonata \\
\hline & 6 & Renault Laguna & Skoda Superb & Mazda 6 & Kia Magentis \\
\hline & 7 & Skoda Superb & Subaru Legacy & Skoda Superb & Peugeot 407 \\
\hline & 8 & Toyota Avensis & Toyota Avensis & Subaru Forester & Skoda Superb \\
\hline & 9 & Volkswagen Jetta & Volkswagen Jetta & Subaru Legacy & Subaru Legacy \\
\hline & 10 & Volkswagen Passat & Volkswagen Passat & Volkswagen Passat & Volkswagen Passat \\
\hline & & \multicolumn{2}{|c|}{ Saab 9-3 } & \multicolumn{2}{|c|}{ Saab 9-5 } \\
\hline & Year & 2008 & 2009 & 2008 & 2009 \\
\hline \multirow{10}{*}{ Panel B: Diesel } & 1 & Audi A4 & Alfa Romeo 159 & Alfa Romeo 159 & Alfa Romeo 159 \\
\hline & 2 & Dodge Avenger & Audi A4 & Audi A4 & Audi A6 \\
\hline & 3 & Honda Accord & Honda Accord & Audi A6 & Dodge Avenger \\
\hline & 4 & Kia Magentis & Kia Magentis & Dodge Avenger & Hyundai Sonata \\
\hline & 5 & Mazda 6 & Mazda 6 & Hyundai Sonata & Jaguar X-Type \\
\hline & 6 & Peugeot 407 & Peugeot 407 & Kia Magentis & Kia Magentis \\
\hline & 7 & Renault Laguna & Subaru Legacy & Lexus Is & Lexus Is \\
\hline & 8 & Toyota Avensis & Toyota Avensis & Peugeot 607 & Skoda Superb \\
\hline & 9 & Volkswagen Jetta & Volkswagen Jetta & Skoda Superb & Subaru Legacy \\
\hline & 10 & Volkswagen Passat & Volvo S80 & Volkswagen Passat & Volvo S80 \\
\hline
\end{tabular}

Table 3: Control group elements disaggregated by year, model (Saab 9-3 and 9-5) and fuel type. A single control group is separately constructed for each of the two Saab car models as well as for each year from 2006 to 2009 and each fuel type. Elements of the control group are chosen to be as close as possible in characteristics space to the characteristics of any given Saab car model. Each control group contains 10 other cars chosen from all possible cars available on the Swedish market between 2005 and 2009. Only models available in a previous year are allowed to be included into a control group. Panel A: Control group for Saab's gasoline models; Panel B: Control group for Saab's diesel models. 


\begin{tabular}{c|ccc}
\hline & $(1)$ & $(2)$ & $(3)$ \\
\hline $\begin{array}{c}\text { Dependent Variable } \\
\text { Sample Period }\end{array}$ & Saab brand sales & Saab 9-3 sales & Saab 9-5 sales \\
& $2006-01 / 2009-12$ & $2006-01 / 2009-12$ & $2006-01 / 2009-12$ \\
\hline \hline Trend x Treatment x Pre-treatment Period & & & \\
\hline & $\mathbf{- 5 . 2 7}$ & $\mathbf{- 3 . 4 9}$ & $\mathbf{- 1 . 7 9}$ \\
GCR FE & & $\mathrm{X}$ & \\
\hline Consumer Confidence & $\mathrm{X}$ & $\mathrm{X}$ & $\mathrm{X}$ \\
Month x Introductions FE:s & $\mathrm{X}$ & $\mathrm{X}$ & $\mathrm{X}$ \\
& $\mathrm{X}$ & & $\mathrm{X}$ \\
\hline Observations & & 96 & $96.56703 .84]$ \\
R-squared & 96 & 0.91 & 0.92 \\
\hline \hline
\end{tabular}

Table 4: Results for triple difference specifications to test the parallel trends assumption. The coefficient of interest is a triple interaction term between a time trend and dummies for the treatment group and the pre-treatment period. Specification 1 shows the parallel trends test for the Saab 9-3, Specification 2 for the Saab 9-5 and Specification 3 for Saab as a brand. 95\% heteroskedasticity-robust confidence intervals are reported within square brackets. The null of parallel trends is not rejected for any of (1)-(3). 


\begin{tabular}{c|ccc}
\hline & $(1)$ & $(2)$ & $(3)$ \\
\hline Dependent Variable & Saab brand sales & Saab 9-3 sales & Saab 9-5 sales \\
Sample Period & $2006-01 / 2009-12$ & $2006-01 / 2009-12$ & $2006-01 / 2009-12$ \\
\hline \hline & & & \\
\hline \multirow{2}{*}{ Bounded Treatment Effect: $[\underline{\delta}, \bar{\delta}]$} & {$[\mathbf{- 2 6 1 . 0 6 , - 2 3 7 . 3 3}]$} & {$[\mathbf{- 2 0 4 . 3 0 , - 1 8 5 . 7 3}]$} & {$[\mathbf{- 5 7 . 1 7 , - 5 1 . 9 7}]$} \\
& {$[-438.46,-142.22]$} & {$[-305.19,-101.82]$} & {$[-105.40,-23.94]$} \\
\hline
\end{tabular}

GCR FE

Consumer Confidence

Month x Introductions FE:s

$\mathrm{X}$

$\mathrm{X}$

X

$\mathrm{X}$

$\mathrm{X}$

$\mathrm{X}$

\begin{tabular}{c|ccc} 
& \multicolumn{3}{c}{} \\
\hline Observations & 96 & 96 & 96 \\
R-squared & 0.766 & 0.757 & 0.716 \\
\hline \hline
\end{tabular}

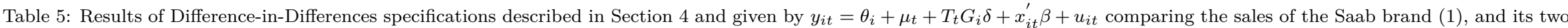

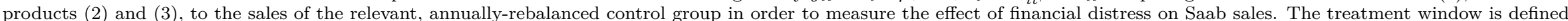

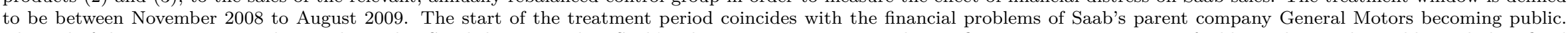

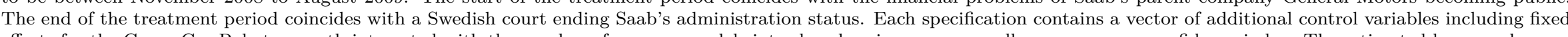

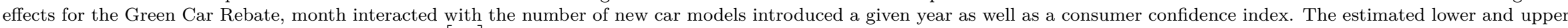

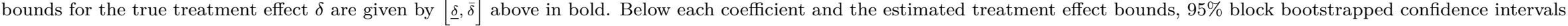
are provided. 


\begin{tabular}{|c|c|c|c|c|c|c|}
\hline & \multicolumn{3}{|c|}{ Control Groups Cars } & \multicolumn{3}{|c|}{ All Cars within Segment } \\
\hline & (1) & $(2)$ & (3) & $(4)$ & $(5)$ & (6) \\
\hline Dependent Variable & Saab brand prices & Saab 9-3 prices & Saab 9-5 prices & Saab brand prices & Saab 9-3 prices & Saab 9-5 prices \\
\hline Sample Period & 2006-2009 & 2006-2009 & 2006-2009 & 2006-2009 & 2006-2009 & 2006-2009 \\
\hline \multirow[t]{2}{*}{ Treatment $\times$ Post } & $-13,043$ & $-4,742$ & $-19,767$ & $-10,865$ & $-2,421$ & $-19,310$ \\
\hline & {$[-27,570,14,842]$} & {$[-30,186,20,702]$} & {$[-28,269,-11,265]$} & {$[-23,625,1,894]$} & {$[-23,045,18,203]$} & {$[-26,566,-12,054]$} \\
\hline Year FE:s & $\mathrm{X}$ & $\mathrm{X}$ & $\mathrm{X}$ & $\mathrm{X}$ & $\mathrm{X}$ & $\mathrm{X}$ \\
\hline Fuel Type FE:s & $\mathrm{X}$ & $\mathrm{X}$ & $\mathrm{X}$ & $\mathrm{X}$ & $\mathrm{X}$ & $\mathrm{X}$ \\
\hline Observations & 141 & 96 & 95 & 582 & 570 & 570 \\
\hline R-squared & 0.938 & 0.906 & 0.974 & 0.980 & 0.980 & 0.980 \\
\hline
\end{tabular}

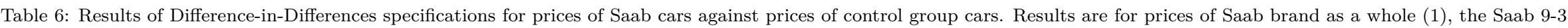

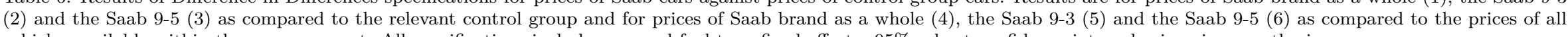
vehicles available within the same segment. All specifications include year and fuel type fixed effects. $95 \%$ robust confidence intervals given in parenthesis. 


\begin{tabular}{|c|c|c|c|c|c|c|}
\hline & \multicolumn{4}{|c|}{ Saab 9-3 } & \multicolumn{2}{|c|}{ Opel Astra } \\
\hline & (1) & $(2)$ & $(3)$ & (4) & $(5)$ & (6) \\
\hline $\begin{array}{l}\text { Control Group Sales } \\
\text { Sample Period }\end{array}$ & $\begin{array}{c}\text { Baseline } \\
\text { 2006-01/2009-12 }\end{array}$ & $\begin{array}{l}\text { Synth. Chars. Only } \\
\text { 2006-01/2009-12 }\end{array}$ & $\begin{array}{l}\text { Synth. Sales Only } \\
2006-01 / 2009-12\end{array}$ & $\begin{array}{c}\text { Synth. Chars. + Sales } \\
\text { 2006-01/2009-12 }\end{array}$ & $\begin{array}{l}\text { Synth. Chars. Only } \\
\text { 2006-01/2009-12 }\end{array}$ & $\begin{array}{c}\text { Synth. Sales Only } \\
2006-01 / 2009-12\end{array}$ \\
\hline Treatment $\times$ Post: $\delta$ & $\begin{array}{c}\mathbf{- 2 0 2 . 2 8} \\
{[-280.31,-124.26]}\end{array}$ & $\begin{array}{c}\mathbf{- 2 2 1 . 4 4} \\
{[-296.94,-145.94]}\end{array}$ & $\begin{array}{c}\mathbf{- 9 2 . 2 4} \\
{[-172.39,-12.08]}\end{array}$ & $\begin{array}{c}\mathbf{- 2 0 2 . 9 2} \\
{[-277.91,-127.94]}\end{array}$ & $\begin{array}{c}\mathbf{- 1 2 7 . 7 2} \\
{[-171.53,-83.91]}\end{array}$ & $\begin{array}{c}-\mathbf{4 8 . 1 1} \\
{[-94.71,-1.51]}\end{array}$ \\
\hline GCR FE & $\mathrm{X}$ & $\mathrm{X}$ & $\mathrm{X}$ & $\mathrm{X}$ & $\mathrm{X}$ & $\mathrm{X}$ \\
\hline Consumer Confidence & $\mathrm{X}$ & $\mathrm{X}$ & $\mathrm{X}$ & $\mathrm{X}$ & $\mathrm{X}$ & $\mathrm{X}$ \\
\hline Month x Introductions FE:s & $\mathrm{X}$ & $\mathrm{X}$ & $\mathrm{X}$ & $\mathrm{X}$ & $\mathrm{X}$ & $\mathrm{X}$ \\
\hline Observations & 96 & 96 & 96 & 96 & 96 & 96 \\
\hline R-squared & 0.764 & 0.759 & 0.650 & 0.706 & 0.823 & 0.784 \\
\hline
\end{tabular}

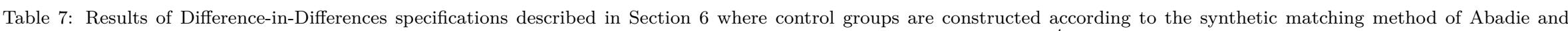

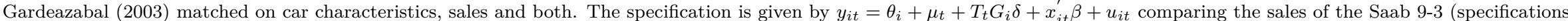

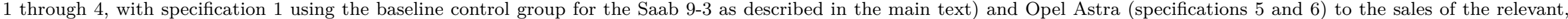

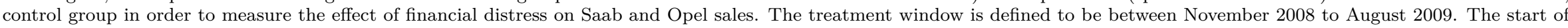

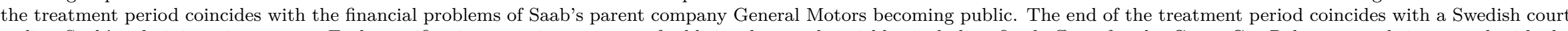

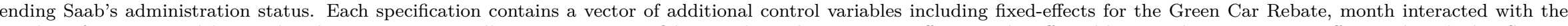

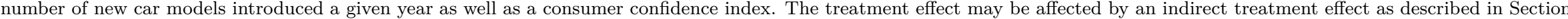

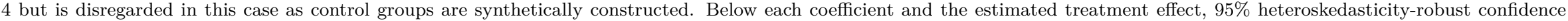
intervals are provided. 
(1)

(2)

(3)

(4)

\begin{tabular}{c|cccc}
\hline $\begin{array}{c}\text { Dependent Variable } \\
\text { Sample Period }\end{array}$ & $\begin{array}{c}\text { Brand Control Group Sales } \\
2005-01 / 2009-12\end{array}$ & $\begin{array}{c}9-3 \text { Control Group Sales } \\
2005-01 / 2009-12\end{array}$ & $\begin{array}{c}9-5 \text { Control Group Sales } \\
2005-01 / 2009-12\end{array}$ & $\begin{array}{c}\text { Total Market Sales } \\
2005-01 / 2009-12\end{array}$ \\
\hline \hline & & & & \\
\hline
\end{tabular}

Month FE:s

Month x Introductions FE:s

Time Trend

Consumer Confidence

GCR FE

$x$

$\mathrm{X}-\mathrm{x}$

$\mathrm{X}-\mathrm{X}$

X

\begin{tabular}{c|c}
\hline Observations & 60 \\
R-squared & 0.88
\end{tabular}

60
0.88

$\mathrm{X}$

$\mathrm{X}$

$\mathrm{X}$

$\mathrm{X}$

$\mathrm{X} \quad \mathrm{X}$

$\mathrm{X} \quad \mathrm{X} \quad \mathrm{X} \quad \mathrm{X}$

$\mathrm{X} \quad \mathrm{X} \quad \mathrm{X} \quad \mathrm{X}$

60
0.85

60

60

0.85

0.75

0.87

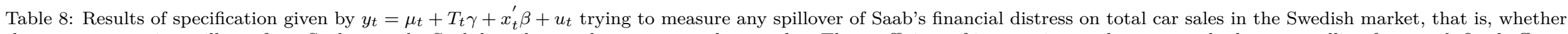

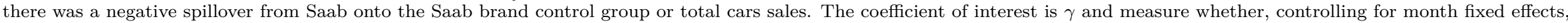

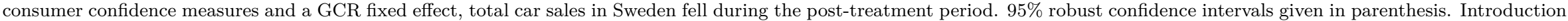
variable excluded in Column (4) as it was constructed for each control group but not for the market as a whole. 


\begin{tabular}{|c|c|c|c|}
\hline & (1) & $(2)$ & (3) \\
\hline Dependent Variable & Saab brand sales & Saab 9-3 sales & Saab 9-5 sales \\
\hline Sample Period & 2006-01/2009-12 & 2006-01/2009-12 & 2006-01/2009-12 \\
\hline \multicolumn{4}{|l|}{ Placebo Test 1: } \\
\hline \multirow{2}{*}{ Bounded Treatment Effect: $[\underline{\delta}, \bar{\delta}]$} & {$[-168.23,-152.94]$} & {$[-548.90,-499.00]$} & {$[-349.20,-317.46]$} \\
\hline & {$[-828.88,375.19]$} & {$[-230.71,863.01]$} & {$[-984.82,7625.58]$} \\
\hline \multicolumn{4}{|l|}{ Placebo Test 2: } \\
\hline \multirow{2}{*}{ Bounded Treatment Effect: $[\underline{\delta}, \bar{\delta}]$} & {$[23.21,-]$} & {$[-13.49,-12.26]$} & {$[2.35,-]$} \\
\hline & {$[-110.22,237.60]$} & {$[-69.31,46.51]$} & {$[-158.64,652.79]$} \\
\hline GCR FE & $\mathrm{X}$ & $\mathrm{X}$ & $\mathrm{X}$ \\
\hline Consumer Confidence & $\mathrm{X}$ & $\mathrm{X}$ & $\mathrm{X}$ \\
\hline Month x Introductions FE:s & $\mathrm{X}$ & $\mathrm{X}$ & $\mathrm{X}$ \\
\hline Observations & 76 & 76 & 76 \\
\hline
\end{tabular}

Table 9: Results of placebo tests to check whether there were significant differences between treatment and control groups pre-treatment. The estimation window excludes the true treatment window. Placebo test 1 is for the period 2008-01/2008-10, thus exactly prior to the true treatment window, whereas Placebo test 2 is set to 2007-02/2007-11 or ending a year prior to the start of the true treatment window. Difference-in-Differences specifications described in Section 4 and given by $y_{i t}=\theta_{i}+\mu_{t}+T_{t} G_{i} \delta+x_{i t}^{\prime} \beta+u_{i t}$ compare the sales of the Saab brand (1), and its two products (2) and (3), to the sales of the relevant, annually-rebalanced control group in order to measure the effect of financial distress on Saab sales. Each specification contains a vector of additional control variables including fixed effects for the Green Car Rebate, month interacted with the number of new car models introduced a given year within the control group as well as a consumer confidence index. The estimated lower and upper bounds for the true treatment effect $\delta$ are given by $[\underline{\delta}, \bar{\delta}]$ above in bold. $95 \%$ block bootstrapped confidence intervals are reported within square brackets below the estimated treatment effect bounds. If the treatment effect is estimated to be positive (Placebo Test 2, columns (1) and (3)) we provide no upper bound, indicated by "-", because the bounds derived in Section 4 assume that the treatment effect is negative and the bounds are therefore no longer applicable. 

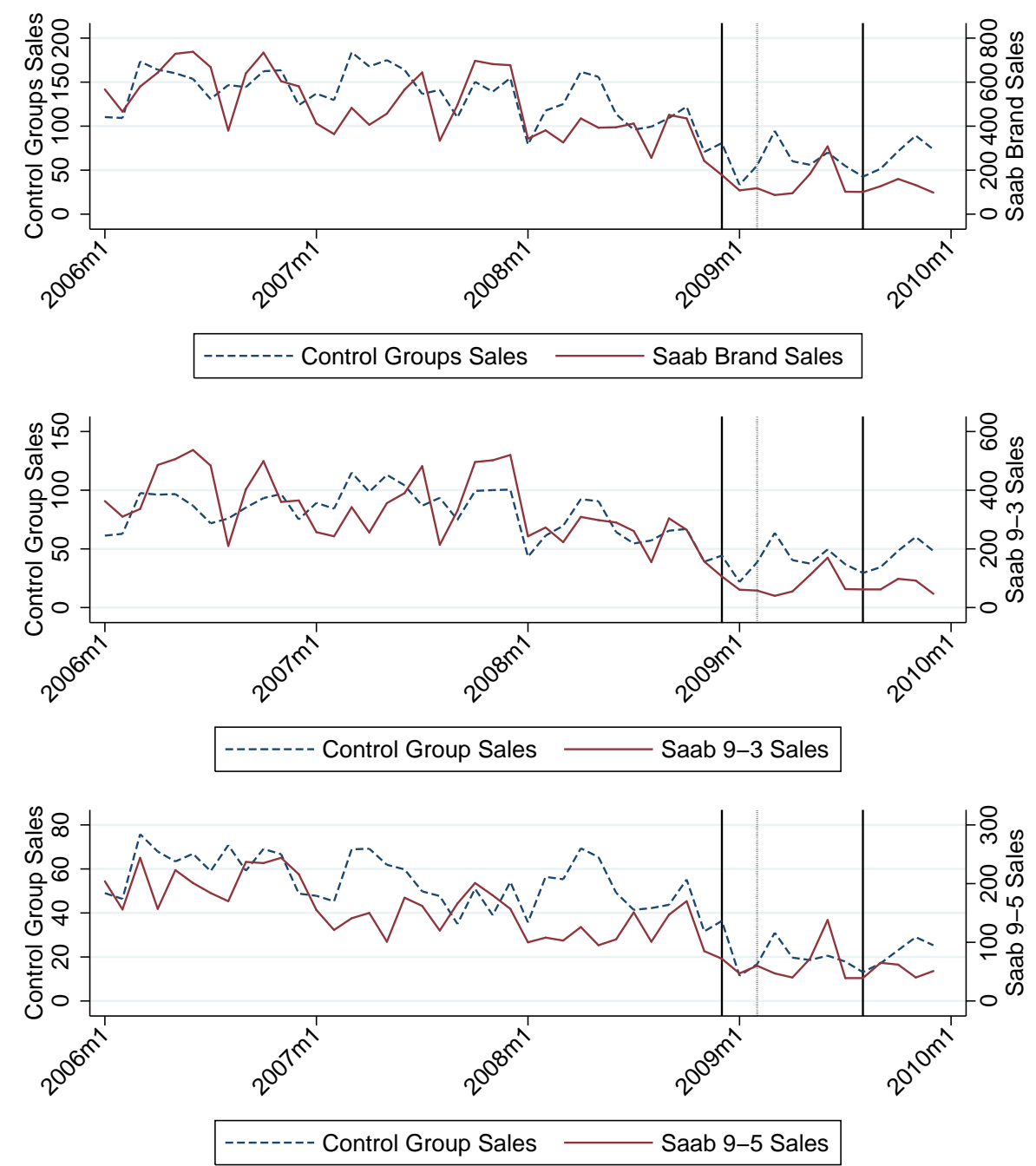

Figure 1: Sales of Saab and of its control group at the monthly frequency from January 2006 to December 2009. Solid vertical lines indicate the treatment period, which begins in November 2008 and ends in August 2009. The start of the treatment period coincides with the financial problems of Saab's parent company General Motors becoming public. The end of the treatment period coincides with a Swedish court ending Saab's administration status. Dashed vertical lines indicate Saab's administration filing in February 2009. Panel 1a (top): Sales of Saab brand and annually rebalanced control group; Panel 1b (middle): Sales of Saab 9-3 and annually rebalanced control group; Panel 1c (bottom): Sales of Saab 9-5 and annually rebalanced control group. 

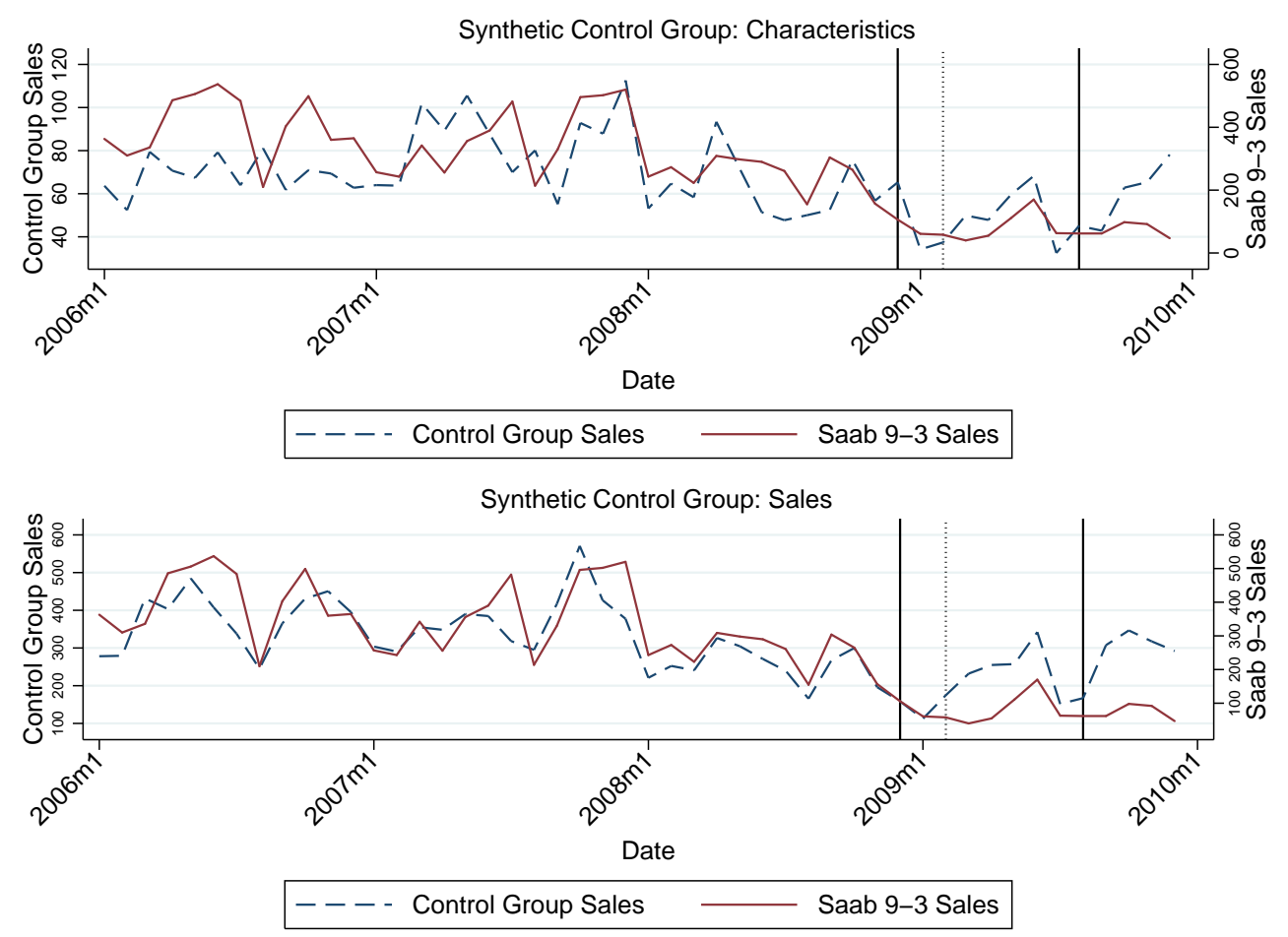

Figure 2: Sales of Saab and of its control group at the monthly frequency from January 2006 to December 2009. Solid vertical lines indicate the treatment period, which begins in November 2008 and ends in August 2009. The start of the treatment period coincides with the financial problems of Saab's parent company General Motors becoming public. The end of the treatment period coincides with a Swedish court ending Saab's administration status. Dotted vertical lines indicate Saab's administration filing in February 2009. Panel 2a (top): Sales of Saab 9-3 and synthetic control group constructed as in Abadie and Gardeazabal (2003) by matching on standardized product characteristics; Panel 2b (bottom): Sales of Saab 9-3 and synthetic control group constructed by matching only on product sales. 

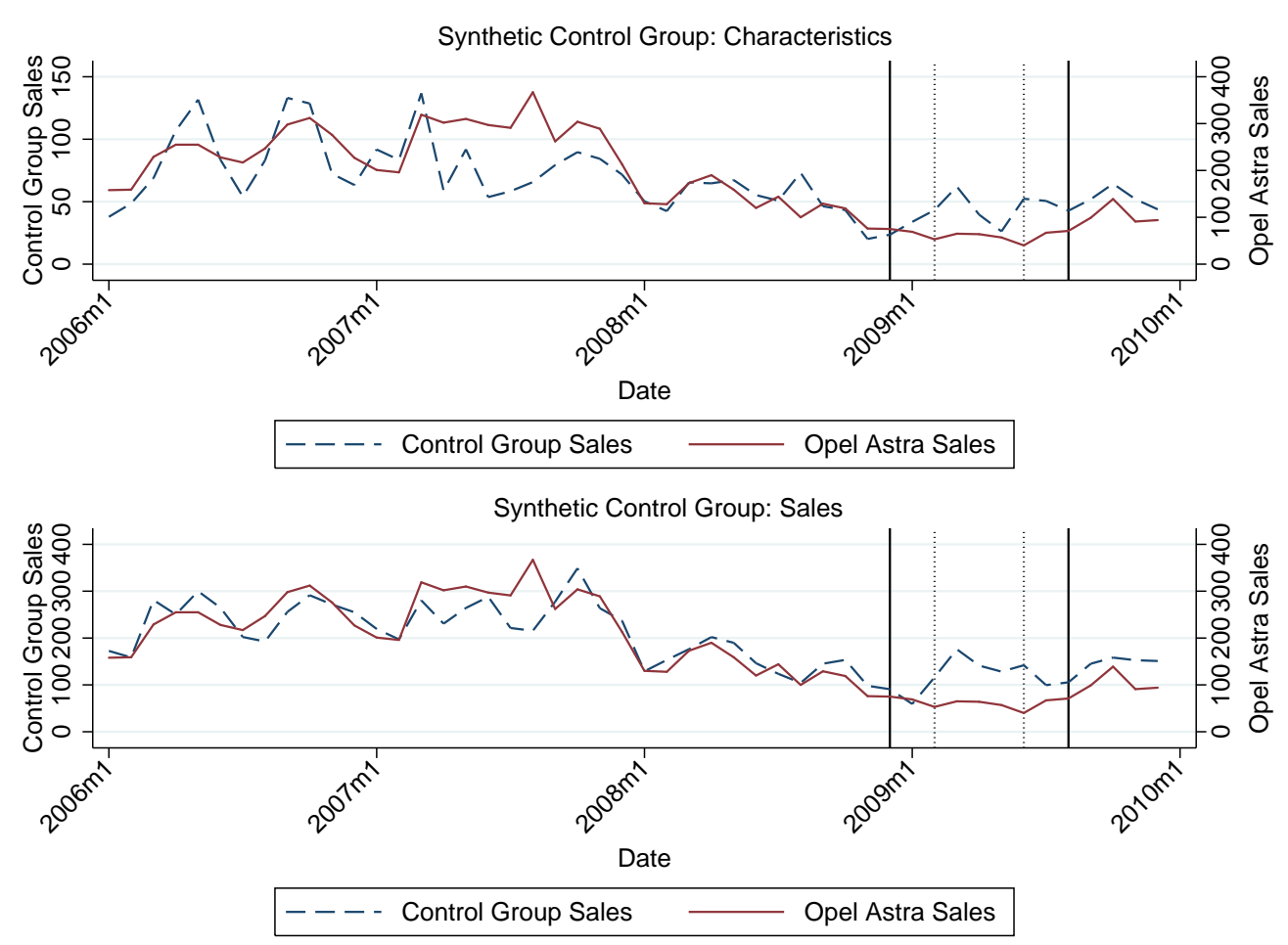

Figure 3: Sales of Opel Astra and sales of relevant control group at a monthly frequency from January 2006 to December 2009 . Solid vertical lines indicate treatment period beginning from November 2008 and ending in August 2009 respectively. The start of the treatment period coincides with the financial problems of Saab's parent company General Motors becoming public. The end of the treatment period coincides with a Swedish court ending Saab's administration status. The first dotted vertical line indicates Saab's administration filing in February 2009 whereas second dotted vertical line indicates GM's bailout in June 2009. Panel 3a (top): Sales of Opel Astra and synthetic control group constructed as in Abadie and Gardeazabal (2003) by matching only on standardized product characteristics; Panel 3b (bottom): Sales of Opel Astra and synthetic control group constructed by matching only on product sales. 


\section{Appendix A: Proofs}

Proof of Proposition 1: From assumption A1, we have that the biased treatment effect $\delta^{*}$ is given by

$$
\delta^{*}=\delta-d
$$

giving the true treatment effect as

$$
\delta=\delta^{*}+d
$$

By assumption $\mathrm{A} 2$, we have that the indirect treatment effect $d$ is bounded

$$
\Delta_{L} \leq d \leq \Delta_{U}
$$

so let $d \leq \Delta_{U}$, then

$$
\delta^{*}+d \leq \delta^{*}+\Delta_{U}
$$

Instead, let $\Delta_{L} \leq d$, then

$$
\delta^{*}+\Delta_{L} \leq \delta^{*}+d
$$

Combining the two cases, we get

$$
\delta^{*}+\Delta_{L} \leq \delta^{*}+d \leq \delta^{*}+\Delta_{U}
$$

Proof of Corollary 1: Under assumptions A2, the indirect treatment effect $d$ is bounded by

$$
0 \leq d \leq-\delta
$$


Under assumption A3, because we use a control group consisting of averages, the indirect treatment effect is going to be $d^{*}=\frac{1}{K} d$ rather than $d$. Let $d^{*}$ also be bounded, with bounds given by

$$
\Delta_{L}^{*} \leq d^{*} \leq \Delta_{U}^{*}
$$

Dividing all terms in (9) by $K \geq 1$, we see that $d^{*}$ is bounded by

$$
\frac{0}{K} \leq \frac{d}{K} \leq-\frac{\delta}{K}
$$

or simply

$$
0 \leq d^{*} \leq-\frac{\delta}{K}
$$

Now, let us rewrite the right hand side of (10) as a function of the estimated treatment effect $\delta^{*}$;

$$
\begin{aligned}
\frac{\delta}{K} & =\frac{\delta^{*}+d^{*}}{K} \\
& =\frac{\left(\delta^{*}+d^{*}\right)(K+1)}{K(K+1)} \\
& =\frac{K \delta^{*}+\delta^{*}+d^{*}-\delta}{K(K+1)} \\
& =\frac{\delta^{*}}{(K+1)}
\end{aligned}
$$

where we use the fact that $\delta^{*}=\delta-d^{*}$ and that $d^{*}=-\frac{\delta}{K}$ at the upper bound. By Proposition 1 , defining the indirect treatment effect as $d^{*}$ as given in (10), we have that under A1 and A2 the true treatment effect is bounded

$$
\delta^{*}+\Delta_{L}^{*} \leq \delta \leq \delta^{*}+\Delta_{U}^{*}
$$

Replacing $\Delta_{L}^{*}, \Delta_{U}^{*}$ in the previous expression by the values given in (10) gives

$$
\delta^{*} \leq \delta \leq \delta^{*}-\frac{\delta}{K}
$$


and replacing the right hand side with the expression from (11) and simplifying,

$$
\delta^{*} \leq \delta \leq \frac{K}{(K+1)} \delta^{*}
$$

Alternatively, for any level of substitution $\lambda \in[0,1]$ we have

$$
\begin{aligned}
\delta^{*} & =\delta-\lambda d^{*} \\
& =\delta+\lambda \frac{\delta}{K} \\
& =\left(1+\frac{\lambda}{K}\right) \delta
\end{aligned}
$$

which implies that

$$
\delta=\frac{K}{K+\lambda} \delta^{*}
$$

Proof of Corollary 2: From Corollary 1 we have that for any level of substitution $\lambda \in[0,1]$

$$
\delta=\frac{K}{K+\lambda} \delta^{*}
$$

If we let $\hat{\delta}$ and $\hat{\delta}^{*}$ be estimators of $\delta$ and $\delta^{*}$ respectively, we have that as $K$ and $\lambda$ are both non-random (because the indirect treatment effect $d$ was assumed to be non-random)

$$
\begin{aligned}
\operatorname{Var}(\hat{\delta}) & =\operatorname{Var}\left(\frac{K}{K+\lambda} \hat{\delta^{*}}\right) \\
& =\left[\frac{K}{K+\lambda}\right]^{2} \operatorname{Var}\left(\hat{\delta^{*}}\right)
\end{aligned}
$$


Proof of Corollary 3: If we let $\hat{\delta}$ and $\hat{\delta}^{*}$ be estimators of $\delta$ and $\delta^{*}$ respectively, we have from Corollary 1 , for any level of substitution $\lambda \in[0,1]$ and size of the control group $K \geq 1$

$$
\hat{\delta}=\frac{K}{K+\lambda} \hat{\delta^{*}}
$$

and from Corollary 2, that

$$
\operatorname{Var}(\hat{\delta})=\operatorname{Var}\left(\frac{K}{K+\lambda} \hat{\delta}^{*}\right)
$$

The standardized estimate of the true treatment effect is

$$
\begin{aligned}
\frac{\hat{\delta}}{\sqrt{\operatorname{Var}(\hat{\delta})}} & =\frac{\frac{K}{K+\lambda} \hat{\delta^{*}}}{\sqrt{\operatorname{Var}\left(\frac{K}{K+\lambda} \hat{\delta^{*}}\right)}} \\
& =\frac{\frac{K}{K+\lambda}}{\frac{K}{K+\lambda}} \frac{\hat{\delta^{*}}}{\sqrt{\operatorname{Var}\left(\hat{\delta^{*}}\right)}} \\
& =\frac{\hat{\delta^{*}}}{\sqrt{\operatorname{Var}\left(\hat{\delta^{*}}\right)}}
\end{aligned}
$$

Proof of Proposition 2: Starting with the definition of $\lambda$,

$$
\lambda=-\frac{\sum_{i=1, i \neq T}^{K^{\prime}} \varepsilon_{i T}}{\varepsilon_{T T}}-\frac{\sum_{i=1, i \neq T}^{K^{\prime \prime}} \varepsilon_{i T}}{\varepsilon_{T T}} \leq-\frac{K^{\prime} \varepsilon_{H}}{\varepsilon_{T T}}-\frac{K^{\prime \prime} \varepsilon_{L}}{\varepsilon_{T T}}
$$

where the first equality follows from E4 and the inequality follwos from E2. By E3 and E1,

$$
\lambda \leq-\frac{K^{\prime} \varepsilon_{H}}{\varepsilon_{T T}}<<1
$$


Proof of Corollary 4: From Corollary 1 one can write $\delta=\frac{K}{K+\lambda} \delta^{*}$. Apply95\% robust confidence intervals given in parenthesis. ing the result in Proposition 2,

$$
\delta \leq \frac{K}{K-\frac{K^{\prime} \varepsilon_{H}}{\varepsilon_{T T}}} \delta^{*}
$$

then equate $K^{\prime}=K$ to obtain the result. 


\section{Appendix B: Empirical Evidence on Elasticities}

We estimate a one-level nested logit demand model for the Swedish new vehicle market in order to document empirical patterns consistent with the assumptions made in the text. The conditional indirect utility to consumer $i$ from purchasing product $j=1, \ldots, J$ is given by

$$
u_{i j}=\delta_{j}+\varepsilon_{i j}=x_{j}^{\prime} \beta-\alpha p_{j}+\xi_{j}+\varepsilon_{i j}
$$

where the mean utility $\delta_{j}$ combines observed exogenous product characteristics $x_{j}^{\prime}$ such as engine power and vehicle size, an observed endogenous product characteristic $p_{j}$, price, and the unobserved (by the econometrician) product characteristic $\xi_{j}$, typically a measure of quality or prestige of a product. The individual-specific part of utility depends on a random term $\varepsilon_{i j}$. Consumers may decide not to purchase any product, in which case they choose the outside good 0 , for which the mean utility $\delta_{0}$ is normalized to zero.

The distribution of the random utility term $\varepsilon_{i j}$ follows the assumptions of a one-level nested logit model. Assume that the market can be partitioned into $G$ mutually exclusive groups, with each group containing $J_{g}$ products with $\sum_{g=1}^{G} J_{g}=J$. If consumers choose one unit of the product to maximize their random utility, the nested logit distributional assumption leads to expressions for choice probabilities (market shares) and the associated estimating equation is given by

$$
\ln \left(s_{j t}\right)-\ln \left(s_{0 t}\right)=x_{j}^{\prime} \beta-\alpha p_{j}+\sigma \ln \left(s_{j t \mid g}\right)+\xi_{j t}
$$

where we introduce the subscript $t$ which indexes time periods (and/or markets) and $s_{j t}$ and $s_{j t \mid g}$ measure product $j$ 's overall and within-nest market shares, respectively. The nesting parameters $\sigma$ measures the heterogeneity of consumer preferences for cars belonging to the same group. Intuitively, products in a given group share a common set of features, for which consumers may have correlated preferences. In our application, we define five groups according to their market segment: subcompact, compact, intermediate, standard, and luxury (an additional group is reserved for the outside good). ${ }^{50}$ Whenever $\sigma=0$, that is, when preferences are uncorrelated for products of the

\footnotetext{
${ }^{50}$ We have also experimented with a number of alternative specifications. For instance, we have considered twolevel nested logit models with choices of (also in reverse order) (i) fuel and segment; (ii) segment and country
} 
same group, one obtains the simple logit model.

The fact that $\xi_{j t}$ is unobserved by the econometrician (but not market participants) leads to a potential correlation between price and the unobserved characteristic, typically requiring the use of instrumental variables. We pursue two strategies in order to identify the price coefficient. First, we rely on the use of product fixed-effects. According to this line of reasoning (Nevo 2001), if unobserved product characteristics are (mostly) time-invariant - as quality and prestige typically are- product fixed-effects should capture the component in $\xi_{j t}$ correlated with prices, with the remaining component consisting of idiosyncratic shocks.

Second, we rely on BLP markup instruments (Berry et al 1995), which are functions of the exogenous product characteristics which should capture changes in prices driven by changes in competition between firms and/or products via their characteristics.

\section{INSERT TABLE B1 ABOUT HERE}

Table B1 reports estimates of alternative nested logit specifications for the Swedish new vehicle market during the pre-treatment period. Columns 1-4 report estimates of uninstrumented specifications differing in the set of controls used: a fixed-effect for domestic brands Saab and Volvo, country of origin fixed-effects, brand fixed-effects and model-fixed-effects (product fixed-effects); in all of these, prices are scaled by per capita income. Column 5 is analogous to Column 4 but replaces the price-income ratio with price. Column 6 uses BLP instruments to control for the endogeneity of price.

The estimates in Table B1 highlight how the introduction of finer fixed-effects - model (product) fixed-effects in the limiting case, see Columns 4 and 5 - attenuate price endogeneity. In fact, the (uninstrumented) own price effects in Column 4 are not too far off from their (instrumented) counterparts in Column 6. These findings suggest that a substantial component of unobservable characteristics of a product are time-invariant.

Thus, the above results lend credence to the assumptions made in the text, such as negligible between-group cross-price elasticities and homogeneity, where the common elasticities $\varepsilon_{H}$ and $\varepsilon_{L}$

of origin of the brand; (iii) segment and whether the product is produced by a domestic brand (Volvo or Saab). The resulting estimates were either inconsistent with utility maximization (e.g. correlations being higher than one, correlation of the sub-group being lower than that of the group) or resulted in implausible elasticity estimates, which led us to settle for the more parsimonious and robust specification reported in the text. 
can be taken as the biggest cross-price effects within and between groups, respectively. 


\begin{tabular}{|c|c|c|c|c|c|c|}
\hline & & & OLS & & & IV \\
\hline & $(1)$ & $(2)$ & (3) & (4) & $(5)$ & (6) \\
\hline Sample Period & 2006-01/2008-11 & 2006-01/2008-11 & 2006-01/2008-11 & 2006-01/2008-11 & $2006-01 / 2008-11$ & 2006-01/2008-11 \\
\hline Price/Income & $\begin{array}{c}-0.099^{* * *} \\
(-4.70)\end{array}$ & $\begin{array}{c}-0.125^{* * *} \\
(-4.57)\end{array}$ & $\begin{array}{c}-0.261^{* * *} \\
(-9.27)\end{array}$ & $\begin{array}{c}-0.244^{* * *} \\
(-4.38)\end{array}$ & & $\begin{array}{c}-1.022^{* *} \\
(-2.27)\end{array}$ \\
\hline Price & & & & & $\begin{array}{c}-0.137^{* * *} \\
(-3.86)\end{array}$ & \\
\hline Segment share & $\begin{array}{l}0.935^{* * *} \\
(143.80)\end{array}$ & $\begin{array}{l}0.934^{* * *} \\
(146.59)\end{array}$ & $\begin{array}{l}0.920^{* * *} \\
(147.18)\end{array}$ & $\begin{array}{l}0.930^{* * *} \\
(173.91)\end{array}$ & $\begin{array}{l}0.931^{* * *} \\
(174.78)\end{array}$ & $\begin{array}{c}0.762^{* * *} \\
(2.98)\end{array}$ \\
\hline HP/Weight & $\begin{array}{c}3.848^{* * *} \\
(6.23)\end{array}$ & $\begin{array}{c}3.833^{* * *} \\
(5.37)\end{array}$ & $\begin{array}{c}5.754^{* * *} \\
(6.79)\end{array}$ & $\begin{array}{c}3.699^{* * *} \\
(3.08)\end{array}$ & $\begin{array}{c}3.642^{* * *} \\
(2.95)\end{array}$ & $\begin{array}{c}6.807^{* * *} \\
(2.86)\end{array}$ \\
\hline $\mathrm{dv}($ manual $)$ & $\begin{array}{c}0.087^{* *} \\
(2.57)\end{array}$ & $\begin{array}{c}0.082^{* *} \\
(2.39)\end{array}$ & $\begin{array}{l}0.038 \\
(1.22)\end{array}$ & $\begin{array}{l}0.052 \\
(1.63)\end{array}$ & $\begin{array}{l}0.050 \\
(1.57)\end{array}$ & $\begin{array}{l}0.020 \\
(0.39)\end{array}$ \\
\hline Time FE's & $\mathrm{X}$ & $\mathrm{X}$ & $\mathrm{X}$ & $\mathrm{X}$ & $\mathrm{X}$ & $\mathrm{X}$ \\
\hline Fuel $\times$ Fuel econ. FE's & $\mathrm{X}$ & $\mathrm{X}$ & $\mathrm{X}$ & $\mathrm{X}$ & $\mathrm{X}$ & $\mathrm{X}$ \\
\hline Domestic FE's & $\mathrm{x}$ & & & & & \\
\hline Country FE's & & $\mathrm{x}$ & & & & \\
\hline Brand FE's & & & $\mathrm{X}$ & & & \\
\hline Model FE's & & & & $\mathrm{x}$ & $\mathrm{x}$ & $\mathrm{x}$ \\
\hline $\begin{array}{l}\text { Observations } \\
\text { Sargan test (p-value) }\end{array}$ & 16,798 & 16,798 & 16,798 & 16,798 & 16,798 & $\begin{array}{c}16,798 \\
0.999\end{array}$ \\
\hline \multicolumn{7}{|l|}{ Avg. Price Elasticities } \\
\hline Own & $\begin{array}{l}-2.40 \\
{[1.70]}\end{array}$ & $\begin{array}{l}-2.97 \\
{[1.77]}\end{array}$ & $\begin{array}{l}-5.15 \\
{[3.06]}\end{array}$ & $\begin{array}{l}-5.51 \\
{[3.28]}\end{array}$ & $\begin{array}{l}-5.40 \\
{[3.19]}\end{array}$ & $\begin{array}{l}-6.77 \\
{[4.01]}\end{array}$ \\
\hline $100 \%$ elastic? & No & No & Yes & Yes & Yes & Yes \\
\hline \multirow[t]{2}{*}{ Cross, same nest } & 0.03 & 0.04 & 0.06 & 0.07 & 0.06 & 0.07 \\
\hline & {$[0.06]$} & {$[0.07]$} & {$[0.12]$} & {$[0.13]$} & {$[0.12]$} & {$[0.13]$} \\
\hline Cross, other nests & $\begin{array}{c}0.00 \\
{[0.01]}\end{array}$ & $\begin{array}{c}0.00 \\
{[0.01]}\end{array}$ & $\begin{array}{c}0.00 \\
{[0.01]}\end{array}$ & $\begin{array}{c}0.00 \\
{[0.01]}\end{array}$ & $\begin{array}{c}0.00 \\
{[0.01]}\end{array}$ & $\begin{array}{l}0.00 \\
{[0.01]}\end{array}$ \\
\hline
\end{tabular}

Table B1: This table reports demand estimates for alternative nested logit specifications for the pre-treatment period. Nests are defined according to five market segments (subcompact, compact, intermediate, standard, luxury). Columns 1-4 report estimates of uninstrumented specifications differing in the set of controls used: a fixed-effect for domestic brands Saab and Volvo, country fixedeffects, brand fixed-effects and model-fixed-effects; in all of them, prices (net of the GCR rebate, if applicable) are scaled by per capita income. Column 5 replaces price/income with price in Column 4. Column 6 uses BLP instruments to account for the endogeneity of price. T-statistics are reported in parentheses, standard errors are reported in square brackets; standard errors are clustered by brand-year and significance levels are given at the $10 \%\left({ }^{*}\right), 5 \%\left({ }^{* *}\right)$, and $1 \%\left({ }^{* * *}\right)$ levels. 


\section{Appendix C: Construction of Synthetic Control Groups}

In this Appendix, we describe in detail the construction of the synthetic control groups of Abadie and Gardeazabal (2003) used in the robustness checks of Section 6.1.

Let $\mathbf{W} \in \mathcal{W}$ be a vector of weights and let the set of all feasible weights be defined as

$$
\mathcal{W}=\left\{\mathbf{x} \in \mathbb{R}^{k} \text { such that } \mathbf{x}^{\prime} \mathbf{1}=1 \text { and } \mathbf{x} \geq 0\right\}
$$

Let $\mathbf{X}_{1}$ be a $j \times 1$ vector of product characteristics for a given Saab product and $\mathbf{X}_{0}$ be a $j \times k$ matrix of product characteristics for $k$ competing products. Let $\mathbf{V}$ denote a diagonal matrix of weights such that for the set of feasible matrices $\mathcal{V}$ weights are non-negative and sum to one. ${ }^{51}$ Further, let $\mathbf{S}_{1}$ be a $t \times 1$ vector of monthly sales for a given Saab product and $\mathbf{S}_{0}$ be a $t \times k$ vector of monthly sales for the competing products. ${ }^{52}$

Equal and Standardized Characteristics Only As described in Section 4, the control groups in this study are constructed by matching Saab products to close competitors, using only standardized characteristics $\overline{\mathbf{X}}$ which are assumed to be equally important. In a similar manner, one can construct a control group by replicating the treated product in terms of characteristics by using the characteristics of all competing products. The weights of each of the elements included in the control group are chosen such that

$$
\mathbf{W}^{*}=\underset{\mathbf{W} \in \mathcal{W}}{\arg \min }\left(\overline{\mathbf{X}}_{1}-\overline{\mathbf{X}}_{0} \mathbf{W}\right)^{\prime} \mathbf{V}\left(\overline{\mathbf{X}}_{1}-\overline{\mathbf{X}}_{0} \mathbf{W}\right)
$$

where $\mathbf{V}$ has $1 / J$ on each diagonal element and the product characteristics are standardized in the same manner as described in the main text. Having replicated the characteristics of the treated product, the sales of the synthetic control group are given by $\mathbf{S}_{1}^{*}=\mathbf{S}_{0} \mathbf{W}^{*}$. The matrix $\mathbf{V}$ is chosen specifically to allow as direct a comparison as possible between the control group constructed in this study and that constructed using the synthetic matching methods of Abadie and Gardeazabal

\footnotetext{
${ }^{51}$ To lower the computational time needed to calculate $\mathbf{V}^{*}$ below, the weights are chosen through a grid search in which the step size is 0.1 for each weight.

${ }^{52}$ For simplicity, sales are aggregated by model rather than by model and fuel type as in the main text. In a similar manner, characteristics are averaged both across model year and fuel type.
} 
(2003).

Sales Only Another possible way to construct the synthetic control group is choose the weight $\mathbf{W}$ in such a way as to replicate the sales of the treatment group as closely as possible in the pre-treatment period. In this way, one ensures that the outcome variables of the treatment and synthetic control groups are as close as possible pre-treatment with the weights of the control group elements instead being chosen such that

$$
\mathbf{W}^{*}=\underset{\mathbf{W} \in \mathcal{W}}{\arg \min }\left(\mathbf{S}_{1}-\mathbf{S}_{0} \mathbf{W}\right)^{\prime}\left(\mathbf{S}_{1}-\mathbf{S}_{0} \mathbf{W}\right)
$$

and where $\mathbf{V}$ has been disregarded as in Abadie and Gardeazabal (2003). In choosing weights this way, one fully disregards the information about product characteristics but ensures that the outcomes of the treatment and control groups are as indistinguishable as possible pre-treatment. Once again, one can calculate the sales of the synthetic control group as $\mathbf{S}_{1}^{*}=\mathbf{S}_{0} \mathbf{W}^{*}$.

Sales and Characteristics As pointed out above, looking only at the sales or characteristics of the treatment or control group elements disregards potential information that could be used in constructing a suitable control group. This is why, to accommodate both the information regarding outcome variables as well as control element characteristics, Abadie and Gardeazabal (2003) proposed choosing the optimal weights as before, by replicating the characteristics of treatment group using control group elements with weights given by

$$
\mathbf{W}^{*}=\underset{\mathbf{W} \in \mathcal{W}}{\arg \min }\left(\mathbf{X}_{1}-\mathbf{X}_{0} \mathbf{W}\right)^{\prime} \mathbf{V}\left(\mathbf{X}_{1}-\mathbf{X}_{0} \mathbf{W}\right)
$$

but choosing relative importance $\mathbf{V}$ so as to give the weights that also provide as close a fit as possible for the outcome variable;

$$
\mathbf{V}^{*}=\underset{\mathbf{V} \in \mathcal{V}}{\arg \min }\left(\mathbf{S}_{1}-\mathbf{S}_{0} \mathbf{W}^{*}(\mathbf{V})\right)^{\prime}\left(\mathbf{S}_{1}-\mathbf{S}_{0} \mathbf{W}^{*}(\mathbf{V})\right)
$$

In this way, all information regarding the treatment and control group elements are taken into account when creating the synthetic control group. 


\section{Supplementary Appendix (Not for Publication)}

\section{Promotional Activity and Investment}

One concern is that the negative effect on the sales of Saab during the treatment period is due to an increase in promotional activity e.g. spending on advertising, by the other manufacturers rather than Saab's financial distress. A key issue in exploring this effect is that data on promotional activity conducted by the different brands is unavailable. We try to explore this issue by first making the assumption that there is no unilateral increase in promotional activity for all the vehicles in a given control group but instead that there was a large increase in promotional activity for the vehicles that had the highest percentual increase in sales from 2008 to 2009. In other words, the vehicles that saw the largest percentual increase in sales were assumed to be the vehicles for which promotion was heavily increased and that also benefited the most. We proceed by completely dropping the two best selling models from all 2009 control groups for both the Saab 9-3 and 9-5 and re-estimating the specifications with eight models in those control groups, as compared to ten for the remaining years. We find that although the treatment effects are halved as compared to the main specification in Table 5 they are still significant at the 95 percent significance level. We feel that this is a conservative way of exploring the question of promotional activity because we are in some sense leaving the "worst performing" models in the control groups for 2009 and thereby severely reducing the estimated treatment effect.

It may also have been the case that GM took the decision to reduce investment in Saab as well as cutting advertising spending in order to save money already prior to the events of late 2008. Advertising costs are posted under "Sales" costs, often together with other costs such as transportation of sold goods in Swedish income statements. We see that apart from a large decline in sales costs between 2005 and 2006, they remain fairly stable until 2008 when they increased by roughly 60 percent from the year before. While this increase may have been due to increased promotional activity and advertising, it is more likely that another post was responsible for this increase.

INSERT TABLE S1 ABOUT HERE 
Overall, the income statements of Saab seem to suggest that during 2006 to 2009 that advertising expenses were fairly stable.

Expenses for research and development however saw a steady decline from 2006 onwards, with the expenses in 2009 being roughly one tenth of those in 2006. While this may help explain the declining sales of Saab during the period, we do not believe this to be a contributing factor to the decline in Saab market shares during the treatment period. The second generation 9-3 was largely unchanged between 2002 and 2012 and the first generation 9-5 unchanged between 1997 and 2009. This would likely cause Saab to be less competitive as other manufacturers introduced improvements to their existing models and new models altogether, something we try to control for directly when looking at technological lagardness, but not the decline during the treatment period itself.

\section{Causality Tests}

We conduct a number of Granger causality tests to assess the exogeneity of the treatment. For each specification, we test whether the fact that Saab was treated can be predicted by lagged sales using a linear probability model. Lagged sales in the pre-treatment period are used to predict the occurrence of being treated using a linear probability model and to see whether declining sales increased the probability that Saab was treated.

\section{INSERT TABLE S2 ABOUT HERE}

Table S2 reports two sets of results, using 1 and 12 lags, for the Saab 9-3, the Saab 9-5 and the Saab brand in Columns 1-3. The null of no significance of lagged sales is comfortably rejected throughout at the standard significance levels suggesting that declining sales pre-treatment are not able to predict Saab's entering into treatment.

\section{Media and Technology}

Accounting for the Technology Channel One concern about DD estimates quantifying consumer responses to Saab's financial distress is that these may be triggered as soon as consumers 
perceive that - due to being in difficulties - the company reduces investment in R\&D and its products do not keep up with competition in technological or quality terms. For instance, the Swedish press reported in 2008 on the postponement of the launch of the new version of the Saab 9-5. This meant that a replacement for the then already severely aged 11 year-old model, was not likely to come until 2010 (SvD 2008c). Following this reasoning, the flattening of Saab's sales over time before it files for administration would have occurred as a consequence of its technological lag with respect to its competitors.

\section{INSERT TABLE S3 ABOUT HERE}

One way to capture the effect of lagging technological development or quality degradation of a product is to construct measures of laggardness and include them as controls when estimating DD effects. ${ }^{53}$ In what follows, we define two measures of distance between products in characteristic space to account for this effect. First, we compute the sum of the Euclidean distances between Saab products and those in the control group, that is, $\sum_{i \in G_{j}} \partial_{i j}$, where $\partial_{i j}$ is the Euclidean distance in characteristic space between a Saab product $j$ and close competitor $i$. Second, we compute the number of negative deviations in characteristics between Saab and the elements of the control group. ${ }^{54}$

\section{INSERT TABLE S4 ABOUT HERE}

The results for models 9-3 and 9-5 are reported in Columns 1-2 of Tables Tables S3 and S4, respectively. In either case, the measures of degradation are statistically insignificant at a $5 \%$ significance level and the DD estimates are similar to those not controlling for technological lag (see columns 2 and 3 of Table 5). In fact, DD estimates tend to strengthen when controlling for the technology channel, regardless of the specific measure considered.

\footnotetext{
${ }^{53}$ While the literature on quality degradation, e.g. Mussa and Rosen (1978), Maskin and Riley (1984), Crawford and Shum (2007), has mostly focused on the active (strategic) choice of degrading quality, e.g. due to market structure, here it appears as a consequence of the company's poor financial health.

${ }^{54} \mathrm{~A}$ negative deviation is one that is perceived negatively by a consumer. For example a lower price than that of another model is viewed positively whereas lower horsepower is viewed negatively.
} 
News articles and printed media Data on newspaper publications was obtained from Affärsdata AB. We collected data on printed newspapers within the two categories "Local/Regional Printed Press" and "Large City Press", and number of articles contained therein, for a given year/month and search word. The search words used were Saab, ${ }^{55}$ Cadillac, Chevrolet, GM, General Motors and Opel.

The information on newspapers available in a given municipality, and the number of articles contained therein, were merged with data from The Press Subsidies Council (Presstödsnämnden) on the annual penetration rates of printed media within each Swedish municipality during 20072009. This gives, for each municipality, the newspapers and respective number of articles containing a given search word with a household penetration greater than 1 percent of all households.

Accounting for the Media Channel Given the potential perception of Saab's financial fragility, the media coverage of Saab's financial situation was likely to increase in the months prior to Saab's filing for administration. In order to measure exposure to news regarding the carmaker Saab, we construct two separate indices; the first index is merely a sum of all newspaper articles printed in newspapers having a household penetration rate greater than 1 percent within a given municipality, year-month and containing the key word "Saab". ${ }^{6}$ The second index gives the number of households within a given municipality that have potentially been exposed to a printed article containing the word "Saab":

$$
I_{t}=\sum_{k} H_{k, t} \sum_{i \in P_{k, t}} \gamma_{i, k, t} n_{i, k, t}
$$

where, for newspaper $i$, for municipality $k$ in period $t, I$ is the index value, $H$ the number of households, $P$ the set of all newspapers with a household penetration of at least 1 percent, $\gamma$ the household penetration rate of a given newspaper and $n$ the number of articles published.

\footnotetext{
${ }^{55}$ Excluding the words JAS, Aero and combinations thereof to mitigate the chances of obtaining articles containing news on Saab Group, the defense manufacturer.

${ }^{56}$ Additionally, we also use the number of articles containing the words "Cadillac", "Chevrolet", "General Motors", "GM" and "Opel" but, qualitatively, the results do not change.
} 
The results for Saab models 9-3 and 9-5 are reported in Columns 4-5 of Tables S3 and S4, respectively. Since media coverage is available only from 2007, the baseline specifications against which Columns 4-5 are to be compared are Columns 3 in Tables S3 and S4. We see that as in the case with the measures of degradation, the measures of media exposure are also insignificant for both the Saab 9-3 and the Saab 9-5.

\section{Miscellaneous Robustness Checks}

Construction of Control Groups We performed a number of robustness checks which did not change the results. First, we constructed control groups of sizes 8 and 12 instead of the standard 10. Next, we dropped models with sales of less than 50 units in a given year from the sample used to construct control groups - again, the results follow through.

Rebalanced vs. Fixed Control Group We perform the entire analysis together with robustness checks also using a control group that is set in 2006 and never rebalanced. The results are both qualitatively and quantitatively similar to those of the main analysis. A brief summary of the results is presented in Figure S1 and Table S5.

Sales-weighted Results We report our most conservative results in the text, namely the case where the models in the control group are equally weighted. We have estimated the very same specifications with models weighted according to sales obtaining stronger results and similar qualitative implications.

Treatment Period Since consumers might react to Saab's administration, we redefine the posttreatment period to start in February 2009 instead of December 2008. The results are robust to this change. We have also experimented with an earlier start of the treatment period, with stronger results. 
Market Shares Our use of sales instead of market shares as the dependent variable in the text is due to the fact that the latter obfuscate the role of the outside good, i.e. the fact that consumers may well not purchase a car at all given the fact that Saab is under administration. As a robustness test, however, we have re-estimated all specifications using market shares rather than sales. While the effect of Saab's administration is still qualitatively significant, the parallel trends tests fail to hold if we are to use market shares of the treatment and control group over the sample period 2006-2009.

Block Bootstrap In our application we calculate $95 \%$ confidence intervals by using a block bootstrap whereby we randomly draw blocks with a length of 6 months with replacement from the original sample and estimate the model given in (8) five hundred times. Thereafter, we use the distribution of the simulated coefficients to determine the $2.5 \%$ and $97.5 \%$ percentiles. We have also conducted this exercise using blocks of 2 and 12 months. The results using the 12-month block length do not differ in any significant way from those using 6-month blocks, suggesting that we adequately capture any dependence in the residuals using a 6-month block. Using blocks of 2-month length give substantially narrower confidence intervals but to be conservative we report all confidence intervals using the 6-month block length.

\section{Additional References}

[1] Crawford, G. S. and M. Shum (2007), Monopoly Quality Degradation and Regulation in Cable Television. Journal of Law and Economics 50, 181-219.

[2] Maskin, E. and J. Riley (1984), Monopoly with Incomplete Information. RAND Journal of Economics 15, 171-96.

[3] Mussa, M. and S. Rosen (1978), Monopoly and Product Quality. Journal of Economic Theory $18,301-17$. 


\section{Supplementary Appendix Tables and Figures}

\begin{tabular}{c|ccccc}
\hline Year & 2005 & 2006 & 2007 & 2008 & 2009 \\
\hline \hline Sales Costs (MSEK)* & $-2,114$ & -690 & -561 & -925 & -652 \\
Research and Development (MSEK)* & $-1,649$ & $-1,613$ & $-1,015$ & -291 & -134 \\
\hline \hline
\end{tabular}

Table S1: Evolution of sales and research and development costs of Saab Automobile AB during the period of 2005 to 2009. Numbers in million SEK. *Source: Income Statement of Saab Automobile AB Annual Reports available from the Swedish Companies Registration Office (Bolagsverket).

\begin{tabular}{lc|ccc}
\hline & & $(1)$ & $(2)$ & $(3)$ \\
\hline & $\begin{array}{c}\text { Dependent Variable } \\
\text { Sample Period }\end{array}$ & $\begin{array}{c}\text { Saab brand sales } \\
2006-01 / 2009-12\end{array}$ & $\begin{array}{c}\text { Saab 9-3 sales } \\
2006-01 / 2009-12\end{array}$ & $\begin{array}{c}\text { Saab 9-5 sales } \\
2006-01 / 2009-12\end{array}$ \\
\hline \hline & & & & \\
Panel A: Lags $=1$ & F-Statistic & 0.00 & 1.68 & 1.68 \\
& & $(0.94)$ & $(0.20)$ & $(0.20)$ \\
Panel B: Lags $=12$ & F-Statistic & 0.07 & 0.08 & $(1.00)$ \\
& & $(1.00)$ & $(1.00)$ & \\
\hline \hline
\end{tabular}

Table S2: Granger Causality tests to check exogeneity of treatment. For each specification, we test whether the fact that Saab was treated can be predicted by lagged sales using a linear probability model. Lagged sales in the pre-treatment period are used to predict the occurrence of being treated using a linear probability model and to see whether declining sales increased the probability that Saab was treated. F-statistic is for the test of the null hypothesis that the coefficients on all lagged sales values are jointly equal to zero. P-value in parenthesis. Specification 1 shows the causality tests for the Saab brand, Specification 2 for the Saab 9-3 and Specification 3 for the Saab 9-5. 


\begin{tabular}{|c|c|c|c|c|c|}
\hline & $(1)$ & $(2)$ & $(3)$ & $(4)$ & $(5)$ \\
\hline Dependent Variable & Saab 9-3 sales & Saab 9-3 sales & Saab 9-3 sales & Saab 9-3 sales & Saab 9-3 sales \\
\hline Sample Period & 2006-01/2009-12 & 2006-01/2009-12 & 2007-01/2009-12 & 2007-01/2009-12 & 2007-01/2009-12 \\
\hline \multirow{2}{*}{ Bounded Treatment Effect: $[\underline{\delta}, \bar{\delta}]$} & {$[-215.40,-195.82]$} & {$[-233.30,-212.09]$} & {$[-166.30,-151.18]$} & {$[-171.30,-155.73]$} & {$[-169.10,-153.73]$} \\
\hline & {$[-315.67,-84.67]$} & {$[-329.19,-98.61]$} & {$[-346.89,-17.50]$} & {$[-701.79,-11.27]$} & {$[-335.03,-15.25]$} \\
\hline \multirow{2}{*}{ Eucl. Dist. } & -6.13 & & & & \\
\hline & {$[-21.36,4.91]$} & & & & \\
\hline \multirow{2}{*}{ Neg. Deviations } & & -3.60 & & & \\
\hline & & {$[-8.32,0.53]$} & & & \\
\hline \multirow{2}{*}{ News Count } & & & & -0.07 & \\
\hline & & & & {$[-0.23,-0.00]$} & \\
\hline \multirow{2}{*}{ Exposure } & & & & & -0.24 \\
\hline & & & & & {$[-0.57,0.03]$} \\
\hline GCR FE & $\mathrm{X}$ & $\mathrm{X}$ & $\mathrm{X}$ & $\mathrm{X}$ & $\mathrm{X}$ \\
\hline Consumer Confidence & $\mathrm{X}$ & $\mathrm{X}$ & $\mathrm{X}$ & $\mathrm{X}$ & $\mathrm{X}$ \\
\hline Month x Introductions FE:s & $\mathrm{X}$ & $\mathrm{X}$ & $\mathrm{X}$ & $\mathrm{X}$ & $\mathrm{X}$ \\
\hline Observations & 96 & 96 & 72 & 72 & 72 \\
\hline R-squared & 0.772 & 0.840 & 0.762 & 0.805 & 0.803 \\
\hline
\end{tabular}

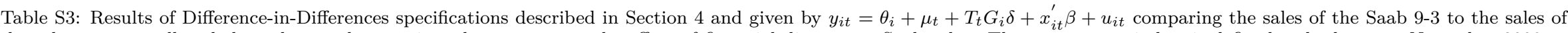

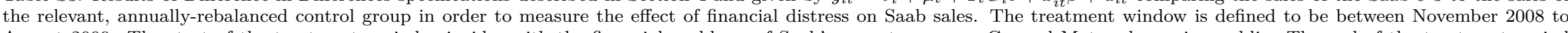

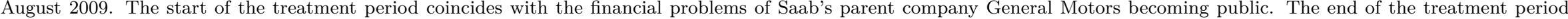

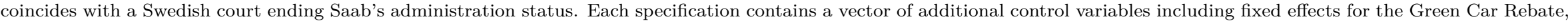

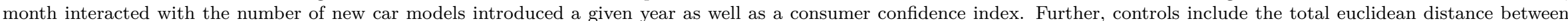

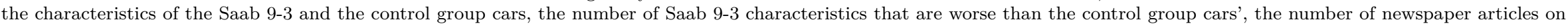

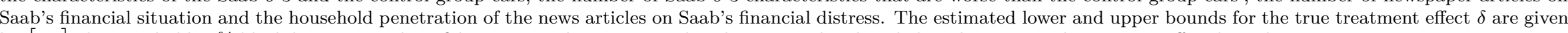
by $[\underline{\delta}, \bar{\delta}]$ above in bold.95\% block bootstrapped confidence intervals are reported within square brackets below the estimated treatment effect bounds. 


\begin{tabular}{|c|c|c|c|c|c|}
\hline & (1) & $(2)$ & (3) & (4) & $(5)$ \\
\hline Dependent Variable & Saab 9-5 sales & Saab 9-5 sales & Saab 9-5 sales & Saab 9-5 sales & Saab 9-5 sales \\
\hline Sample Period & 2006-01/2009-12 & 2006-01/2009-12 & 2007-01/2009-12 & 2007-01/2009-12 & 2007-01/2009-12 \\
\hline \multirow{2}{*}{ Bounded Treatment Effect: $[\underline{\delta}, \bar{\delta}]$} & {$[-70.58,-64.16]$} & {$[-69.68,-63.35]$} & {$[-34.32,-31.20]$} & {$[-34.90,-31.73]$} & {$[-34.49,-31.36]$} \\
\hline & {$[-105.61,-15.37]$} & {$[-98.01,-20.25]$} & {$[-77.84,29.27]$} & {$[-78.45,17.39]$} & {$[-78.61,7.62]$} \\
\hline \multirow{2}{*}{ Eucl. Dist. } & -2.92 & & & & \\
\hline & {$[-5.48,0.61]$} & & & & \\
\hline \multirow{2}{*}{ Neg. Deviations } & & -1.60 & & & \\
\hline & & {$[-2.71,0.27]$} & & & \\
\hline \multirow{2}{*}{ News Count } & & & & -0.01 & \\
\hline & & & & {$[-0.04,0.06]$} & \\
\hline \multirow{2}{*}{ Exposure } & & & & & -0.04 \\
\hline & & & & & {$[-0.12,0.13]$} \\
\hline GCR FE & $\mathrm{X}$ & $\mathrm{X}$ & $\mathrm{X}$ & $\mathrm{X}$ & $\mathrm{X}$ \\
\hline Consumer Confidence & $\mathrm{X}$ & $\mathrm{X}$ & $\mathrm{X}$ & $\mathrm{X}$ & $\mathrm{X}$ \\
\hline Month x Introductions FE:s & $\mathrm{X}$ & $\mathrm{X}$ & $\mathrm{X}$ & $\mathrm{X}$ & $\mathrm{X}$ \\
\hline Observations & 96 & 96 & 72 & 72 & 72 \\
\hline R-squared & 0.837 & 0.848 & 0.776 & 0.785 & 0.785 \\
\hline
\end{tabular}

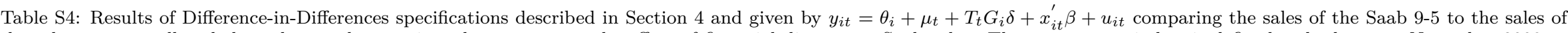

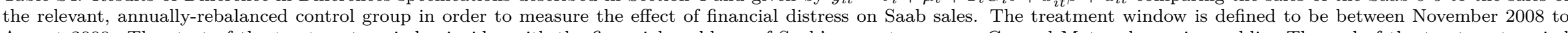

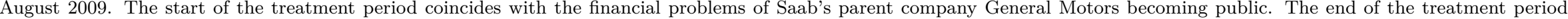

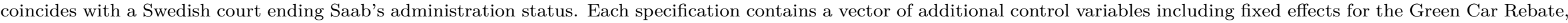

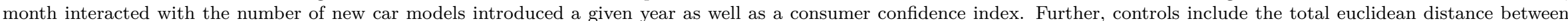

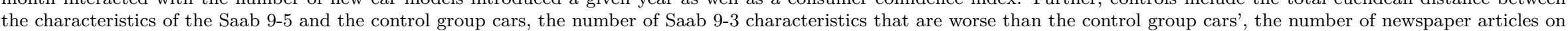

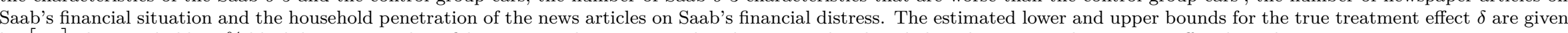
by $[\underline{\delta}, \bar{\delta}]$ above in bold. $95 \%$ block bootstrapped confidence intervals are reported within square brackets below the estimated treatment effect bounds. 


\begin{tabular}{c|ccc}
\hline & $(1)$ & $(2)$ & $(3)$ \\
\hline Dependent Variable & Saab brand sales & Saab 9-3 sales & Saab 9-5 sales \\
Sample Period & $2006-01 / 2009-12$ & $2006-01 / 2009-12$ & $2006-01 / 2009-12$ \\
\hline \hline & & & \\
\hline \multirow{2}{*}{ Bounded Treatment Effect: $[\underline{\delta}, \bar{\delta}]$} & {$[\mathbf{- 2 8 3 . 5 1 , - 2 5 7 . 7 4}]$} & {$[\mathbf{- 2 1 8 . 1 0 , - 1 9 8 . 2 7}]$} & {$[\mathbf{- 6 6 . 7 1 , - 6 0 . 6 5}]$} \\
& {$[-421.55,-158.89]$} & {$[-326.24,-115.96]$} & {$[-119.69,-26.57]$} \\
\hline GCR FE & & & \\
Consumer Confidence & $\mathrm{X}$ & $\mathrm{X}$ & $\mathrm{X}$ \\
Month x Introductions FE:s & $\mathrm{X}$ & $\mathrm{X}$ & $\mathrm{X}$ \\
& $\mathrm{X}$ & $\mathrm{X}$ & $\mathrm{X}$ \\
\hline Observations & & 96 & 96 \\
R-squared & 0.769 & 0.763 & 0.710 \\
\hline \hline
\end{tabular}

Table S5: Results of Difference-in-Differences specifications described in Section 4 and given by $y_{i t}=\theta_{i}+\mu_{t}+T_{t} G_{i} \delta+x_{i t}^{\prime} \beta+u_{i t}$ comparing the sales of the Saab brand (1), and its two products (2) and (3), to the sales of the relevant, fixed 2006 control group in order to measure the effect of financial distress on Saab sales. The treatment window is defined to be between November 2008 to August 2009. The start of the treatment period coincides with the financial problems of Saab's parent company General Motors becoming public. The end of the treatment period coincides with a Swedish court ending Saab's administration status. Each specification contains a vector of additional control variables including fixed effects for the Green Car Rebate, month interacted with the number of new car models introduced a given year as well as a consumer confidence index. The estimated lower and upper bounds for the true treatment effect $\delta$ are given by $[\underline{\delta}, \bar{\delta}]$ above in bold. $95 \%$ block bootstrapped confidence intervals are reported within square brackets below the estimated treatment effect bounds. 

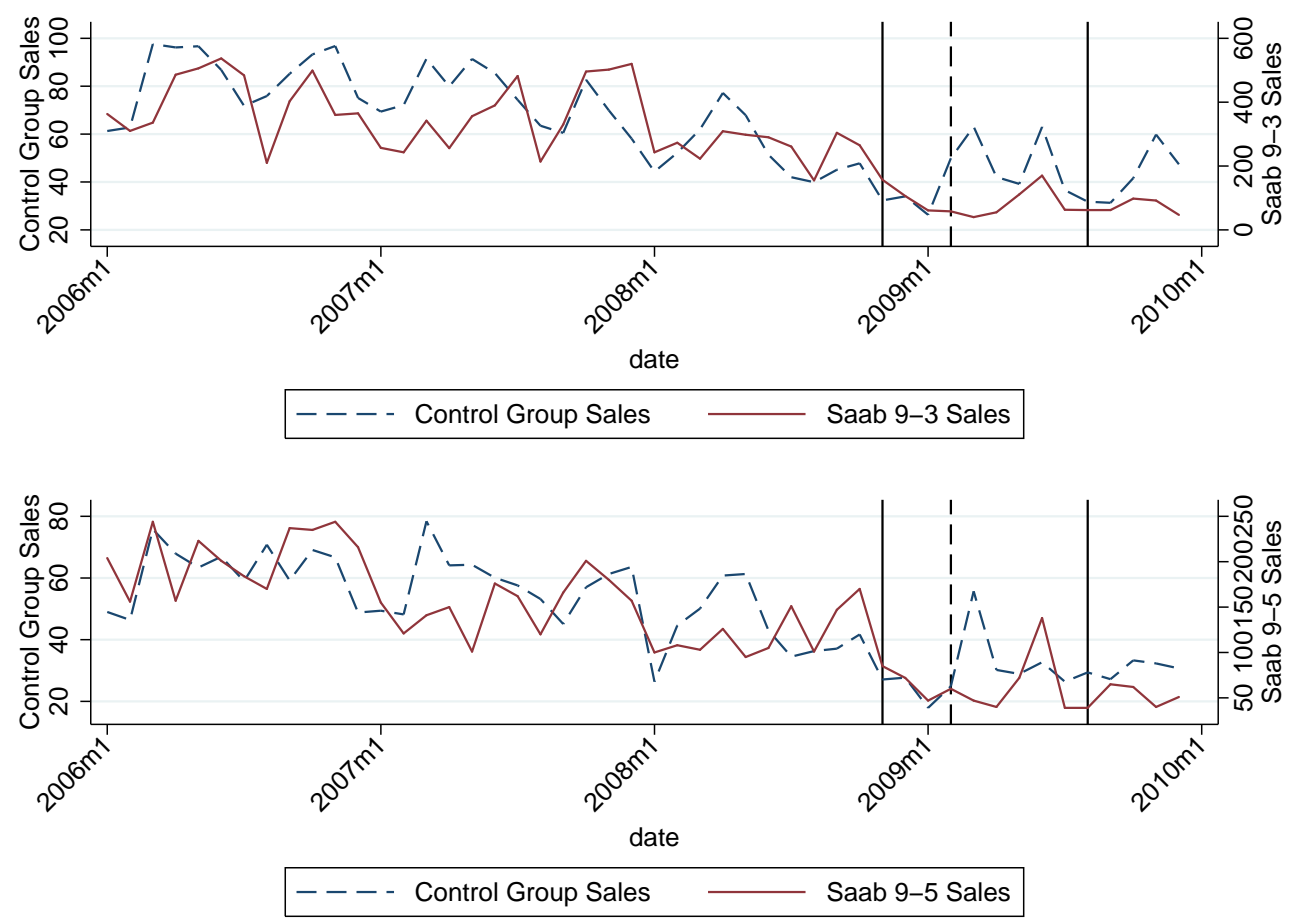

Figure S1: Sales of Saab and sales of relevant control group at a monthly frequency from January 2006 to December 2009. Solid vertical lines indicate beginning from November 2008 and ending in August 2009 respectively. The start of the treatment period coincides with the financial problems of Saab's parent company General Motors becoming public. The end of the treatment period coincides with a Swedish court ending Saab's administration status. Broken vertical line indicates Saab's administration filing in February 2009. Panel S1a (top): Sales of Saab 9-3 and fixed 2006 control group; Panel S1b (bottom): Sales of Saab 9-5 and fixed 2006 control group. 